\title{
Las autorizaciones para la construcción y puesta en funcionamiento en Andalucía de instalaciones energéticas con fuentes renovables*
}

\author{
Concepción Barrero Rodríguez \\ Catedrática de Derecho Administrativo \\ Universidad de Sevilla
}

\begin{abstract}
SUMARIO: I. INTRODUGCIÓN. LA GOMPLEJIDAD DE LA MATERIA. II. DOS CUESTIONES GENERALES DE SINGULAR RELEVANCIA: LA NATURALEZA DE LAS AUTORIZACIONES Y EL RÉGIMEN APLICABLE EN LOS CASOS DE VARIACIÓN NORMATIVA. 1. La naturaleza de las autorizaciones. Su carácter reglado. 2. El régimen aplicable en los casos de variación normativa. III. LOS PROCEDIMIENTOS DE AUTORIZACIÓN: CARACTERÍSTICAS BÁSICAS Y PROBLEMAS FUNDAMENTALES. 1. El permiso de acceso y conexión a las redes. La atribución de funciones públicas a entidades privadas. A. La necesidad de procedimientos de priorización. B. Las tecnologías gestionables. a) El procedimiento y la resolución de priorización. b) La vigencia del punto de conexión y su prórroga. Una regulación anómala desde las categorías propias del Derecho Administrativo. C. Las tecnologías no gestionables. La energía eólica. D. Las tecnologías no gestionables. La energía solar fotovoltaica. a) El acceso y conexión a la red. Los problemas que suscita. b) La vigencia del punto de conexión y sus prórrogas. Las dudas y soluciones del Decreto 9/2011. 2. La autorización para la construcción y puesta en funcionamiento de las instalaciones de producción. A. La autorización del anteproyecto de instalación: a) La solicitud: El informe de compatibilidad urbanística. b) La tramitación del procedimiento. En particular, la inclusión en él de las autorizaciones previstas por la legislación sectorial. c) La resolución: Las vías posibles para su impugnación. B. La aprobación del proyecto de ejecución. C. La autorización de explotación. D. Autorización energética y licencia urbanística. 3. La concesión de instalación acogida al régimen especial de producción. IV. GONSIDERACIÓN FINAL. ¿ES NEGESARIA O CONVENIENTE LA REFORMA DEL RÉGIMEN VIGENTE?
\end{abstract}

* Trabajo realizado en el ámbito del Grupo de Investigación "DER 2010-18571: Régimen jurídico de los recursos naturales". 


\title{
RESUMEN
}

La producción de energía a partir de fuentes renovables ha experimentado en los últimos años un extraordinario auge, lo que ha propiciado un importante desarrollo normativo necesitado de análisis y reflexión en numerosos aspectos. Este estudio tiene por objeto el examen de las autorizaciones necesarias para la construcción y puesta en funcionamiento de instalaciones de generación eléctrica a partir de tales fuentes exponiendo sus rasgos más destacados y los problemas y dudas que plantea la regulación vigente.

Palabras claves:

Energías renovables, autorización, procedimiento administrativo, impugnación de los actos.

\begin{abstract}
Energy production from renewable sources has experienced in recent years an extraordinary boom, which has led to a significant policy development needed to be examined on many aspects. This study aims to review, from the procedural point of view essentially, permits, which concur in the construction and operation of facilities of this nature, analyzing their prominent features and exposing the problems and doubts that the current regulations poses.
\end{abstract} suits.

Keywords: renewable energy, authorization, administrative proceeding,

\section{INTRODUGGIÓN. LA GOMPLEJIDAD DE LA MATERIA}

La sustitución de las fuentes convencionales de energía por fuentes renovables se ha convertido en el eje fundamental de una nueva política energética a nivel mundial que asume entre sus objetivos básicos el de la protección del medio ambiente. No es extraño, por ello, que la regulación de esta clase de energía, y en particular su fomento, haya irrumpido con fuerza en el Derecho comunitario de los últimos años del siglo XX y primeros del siglo XXI. Un fenómeno al que tampoco es ajeno el importante desarrollo tecnológico que se está produciendo en un sector en el que España, según declara el "Plan de acción de energías renovables (PANER) 2011-2020", "se ha posicionado como líder" a nivel internacional ${ }^{1}$.

\footnotetext{
${ }^{1}$ Este plan puede consultarse en la página web del Ministerio de Industria, Turismo y Comercio.
} 
El régimen jurídico de las energías renovables presenta numerosas cuestiones de interés ${ }^{2}$. Entre ellas, la relativa a las autorizaciones necesarias para la construcción y puesta en funcionamiento de las instalaciones de producción de energía. Aunque esta actividad se desarrolla, como establece el artículo 11.1 de la Ley 54/1997, de 27 de noviembre del Sector eléctrico (LSE), "en un régimen de libre competencia", queda sometida, como la propia norma determina en su artículo 21.1, "al régimen de autorización administrativa previa en los términos establecidos en esta Ley y en sus disposiciones de desarrollo". Este régimen se caracteriza por su complejidad como consecuencia de un conjunto de factores de índole diversa. Así.

1. El reparto competencial existente en la materia, que se traduce, en lo que aquí interesa, en instalaciones cuya construcción y puesta en funcionamiento ha de ser autorizada por las Comunidades Autónomas e instalaciones, de otra parte, en las que la competencia pertenece a la Administración del Estado. Son las determinadas en el artículo 3.2.a) de la LSE: las de "generación de potencia eléctrica instalada superior a $50 \mathrm{~mW}$ eléctricos, las de transporte secundario y distribución que excedan del ámbito territorial de una Comunidad Autónoma, y todas las instalaciones de transporte primario"3. Al Estado corresponde, también, la autorización de instalaciones de generación eléctrica en el mar territorial en aplicación del RD 1028/2007, de 20 de julio ${ }^{4}$.

2. La LSE excluye además en su Disposición Final $1^{a}$.2 el carácter básico de "las referencias a los procedimientos que serán regulados por la Administración competente, ajustándose en todo caso a lo establecido en la Ley 30/1992, de Régimen jurídico de las Administraciones Públicas y del procedi-

\footnotetext{
${ }^{2}$ Sobre la definición de esta clase de energías puede verse el epígrafe correspondiente de la monografia de LÓPEZ SAKO, M.J., Regulación y autorización de los parques eólicos, Thomson-Civitas, Navarra, 2008, págs. 53-63.

${ }^{3}$ Sobre el particular puede consultarse RODRÍGUEZ-ARANA MUÑOZ, J. "La distribución de competencias entre el Estado y las Comunidades Autónomas en materia de energía" (AAVV Tratado de regulación del sector eléctrico, T. I, Thomson Aranzadi-Iberdrola, Navarra, 2009, págs. 479-504) o BACIGALUPO SAGGESE, M. "La distribución de competencias entre el Estado y las Comunidades Autónomas en materia de energías renovables" (Tratado de energías renovables, Vol I, BECKER, F., CAZORLA, L.M y J. MARTÍNEZ-SIMANCAS (Dir.), ArazandiIberdrola, Navarra, 2010, págs. 49-78).

${ }^{4}$ Aunque esta disposición es aplicable a todas las instalaciones ubicadas en el mar territorial, el procedimiento que regula está específicamente previsto para los parques eólicos. La norma solo dedica un artículo, el 32, el único precepto del Título III, a "otras tecnologías de generación marina".
} 
miento administrativo común". Ello significa que no existe un régimen unitario para los procedimientos de autorización que ocupan nuestra atención. Las Comunidades Autónomas, y así lo han hecho ya muchas de ellas, pueden regular la tramitación que ha de seguirse para la concesión de las autorizaciones que sean de su competencia. Andalucía no cuenta con una regulación general de estos procedimientos, aunque sí con un conjunto de normas dispersas en el ámbito de concretas energías renovables. Supletoriamente se aplicará el Derecho del Estado en el que destacan dos disposiciones: los RRDD 1955/2000, de 27 de diciembre, sobre actividades de transporte, distribución, comercialización, suministro y procedimientos de autorización de instalaciones de energía eléctrica y 661/2007, de 25 de mayo, de producción de energía eléctrica en régimen especial, objeto de importantes modificaciones por las normas de igual rango 198/2010, de 26 de febrero y 1565/2010, de 19 de noviembre.

3. Ha de tenerse en cuenta también, desde una perspectiva distinta, que para la construcción y puesta en funcionamiento de una instalación de generación eléctrica no es suficiente con la específica autorización prevista por la LSE y sus disposiciones de desarrollo. Estamos ante actividades en las que concurren una pluralidad de títulos habilitantes que responden a la salvaguarda de bienes jurídicos diversos cuya garantía viene conferida a órganos distintos de la Administración Pública e, incluso, a Administraciones diferentes. En efecto, en toda instalación energética confluyen al menos, como destaca la jurisprudencia, dos valores a tutelar: la garantía del suministro de energía eléctrica, calificado por la propia Exposición de Motivos de la LSE de "esencial para el funcionamiento de nuestra sociedad"; y la conservación del medio ambiente, fin al que se ordenan otras muchas disposiciones ${ }^{5}$. A estos dos intereses habrá que sumar los derivados de la ordenación territorial y urbanística y aquellos otros que, atendiendo a las características de cada instalación concreta, vengan impuestos por otras disposiciones de cuya aplicación pueda resultar la necesidad de otras autorizaciones. Son los casos, en algunos ejemplos tomados de la jurisprudencia, de la autorización de los órganos de Cultura por exigencias derivadas de la protección del Patrimonio arqueológico ${ }^{6}$ o la del Ministerio de Defensa si, como era el caso enjuiciado por la Sentencia del Tribunal Superior de Justicia

\footnotetext{
${ }^{5}$ La doctrina se ha referido ampliamente al valor de las energías renovables para la consecución de la protección ambiental sin detrimento del suministro eléctrico. Así, y entre otros, ARAGÓN REYES, M. ("Constitución, medio ambiente y energías renovables", Tratado de energías renovables, Vol I, BECKER, F., CAZORLA, L.M y J. MARTÍNEZ-SIMANCAS (Dir.), op. cit., págs. 27-48).

${ }^{6}$ Sentencia del Tribunal Superior de Justicia de Galicia de 4 de abril de 2002 (JUR 221004).
} 
de Madrid de 5 de abril de $2005^{7}$, el parque eólico que pretendía instalarse se encontraba en terrenos colindantes a un campo de tiro del ejército.

Esta concurrencia de intereses públicos diversos y esta pluralidad, por consiguiente, de títulos habilitantes es reconocida por la LSE que establece que las autorizaciones para instalaciones de producción serán otorgadas "sin perjuicio de las concesiones y autorizaciones que sean necesarias de acuerdo con otras disposiciones que resulten aplicables y en especial las relativas a la ordenación del territorio y el medio ambiente"s.

4. Ahora bien, si centramos exclusivamente nuestra atención en la autorización exigida por la LSE para la construcción y explotación de instalaciones de energía, la denominada autorización energética, hemos de tener en cuenta otro dato importante. Esta autorización, en los términos que ahora desarrollaremos, es, en realidad, el resultado de varias resoluciones administrativas distintas. A saber: a) La autorización del anteproyecto de la instalación; b) La aprobación del proyecto concreto de ejecución; y c) La autorización de explotación o acta de puesta en servicio.

5. Finalmente debe tenerse en cuenta que el interesado en una instalación de este tipo ha de contar además con el permiso de acceso y conexión a la red. Y si, como con carácter general ocurre en el ámbito de las energías renovables, pretende que su instalación quede sujeta al régimen especial de producción ${ }^{9}$, tendrá que disponer igualmente del reconocimiento de esta condición.

En definitiva, nos encontramos ante un modelo complejo, complejidad que se acrecienta por la propia dificultad técnica de la materia y los continuos cambios normativos a los que se ve sometida como consecuencia, en buena medida, del importante desarrollo tecnológico que se está produciendo en este sector. Esta situación no es exclusiva de España. La Unión europea situaba en

${ }^{7}$ RJCA 567.

${ }^{8}$ Artículos 21.3, 28.3, 36.3 y 40.3.

La norma resuelve así el que, como señalara LÓPEZ MENUDO, F., ha constituido siempre un punto de gran interés dentro del régimen de las autorizaciones, objeto además de no pocas controversias. ("Voz expectativa", Enciclopedia Jurídica Civitas, Vol. I, Madrid, 1995, pág. 714).

${ }^{9} \mathrm{El}$ artículo 27.1 de la LSE establece los casos en los que procede este régimen. El RD $661 / 2007$, en términos que han sido objeto de modificación importante por el 1565/2010, de 19 de noviembre, regula la actividad de producción de energía bajo este específico régimen.

Sobre este régimen puede verse NEBREDA PEREZ, J.M. Aspectos jurídicos de la producción de energía eléctrica en régimen especial, Thomson Civitas, Navarra, 2007. 
el año 2005 entre los problemas más relevantes del mercado de las energías renovables el de la descoordinación entre las muchas autoridades con competencias en la materia ${ }^{10}$. No es extraño, por ello, que la Directiva 2009/28, de 23 de abril, de fomento del uso de energía procedente de fuentes renovables, exija a los Estados que "los procedimientos administrativos se racionalicen y se aceleren en el nivel administrativo adecuado" teniendo "en cuenta las peculiaridades de cada tecnología de las energías renovables" "1. En España, no obstante, el problema se ve, sin duda, agravado por el fuerte grado de descentralización interna.

\section{DOS CUESTIONES GENERALES DE SINGULAR RELEVANCIA: LA NATURALEZA DE LAS AUTORIZACIONES Y EL RÉGIMEN APLICABLE EN LOS CASOS DE VARIACIÓN NORMATIVA}

Con carácter previo al examen de los procedimientos para la obtención de los permisos necesarios para la puesta en funcionamiento de una instalación de producción eléctrica, proceden algunas consideraciones sobre dos cuestiones generales de gran interés teórico y que son, además, fuente de importantes problemas en la práctica.

\section{La naturaleza de las autorizaciones. Su carácter reglado.}

La autorización energética tiene, como declara el artículo 21.1 de la LSE y reconoce la jurisprudencia en su aplicación, "carácter reciembre.

${ }^{10}$ Vid. Informe de la Comisión al Consejo y al Parlamento, núm. 627/2005, de 7 de di-

${ }^{11}$ Señala además la Directiva que es "patente la falta de normas transparentes y de coordinación entre los diferentes organismos de autorización" lo que dificulta el despliegue de estas energías, de ahí que su artículo 13 establezca que "los Estados velarán porque las normas relativas a los procedimientos de autorización y concesión de licencias de instalaciones e infraestructuras conexas sean proporcionadas y necesarias". Y en particular, deberán adoptar las medidas apropiadas para garantizar que "sin perjuicio de las diferencias entre las estructuras administrativas y la organización de los Estados miembros, las responsabilidades respectivas de los organismos administrativos nacionales, regionales y locales en materia de procedimientos de autorización, certificación y concesión de licencias se coordinen y definan claramente, lo que comprende la planificación espacial, con calendarios transparentes para la determinación de las solicitudes de planificación y construcción". Igualmente se deberá proporcionar "a los solicitantes, al nivel apropiado, información exhaustiva sobre la tramitación de las solicitudes de autorización, certificación y licencia para instalaciones de energía renovable y sobre las ayudas disponibles para los solicitantes". 
glado"12. En efecto, la Administración debe limitarse a comprobar si la instalación proyectada cumple o no con los requisitos dispuestos en las disposiciones en vigor. Siendo ello así, ha de llamarse la atención, si embargo, sobre el fuerte componente técnico de unas normas que reenvían a disciplinas no jurídicas y que se basan en conceptos jurídicos indeterminados cuya concreción exige de los conocimientos aportados por la ciencia y la técnica. Parámetros tales como "la reserva de capacidad de la red" o "la capacidad (de una instalación) para gestionar el recurso natural en cuestión" confieren a la Administración un poder de análisis y valoración de los distintos presupuestos de hecho de las normas que la sitúan claramente en el ámbito de la discrecionalidad técnica. Es, por ello, que la Administración deberá siempre ofrecer una motivación suficiente de sus decisiones ${ }^{13}$, una explicación fundada de por qué deniega, por ejemplo, un determinado punto de acceso a la red o lo acepta en unas condiciones distintas a las propuestas por el solicitante, o de por qué no autoriza, en su caso, un determinado proyecto de planta. Esta motivación constituye una garantía básica de los interesados y contribuye decididamente al eventual control judicial de las decisiones adoptadas.

\section{El régimen aplicable en los casos de variación normativa.}

La larga duración de estos procedimientos y la frecuencia con la que cambian las disposiciones reguladoras de la materia, hace que no sea raro que se produzcan cambios normativos durante la tramitación de los sucesivos permisos que concluyen con la puesta en servicio de una instalación. Ello nos sitúa ante una pregunta trascendental y clásica en Derecho: la de si las autorizaciones se conceden de conformidad con el régimen vigente en la fecha de la solicitud o en aplicación del establecido en el momento de su concesión. En su respuesta pugnan soluciones de sentido contrario. De una parte, la garantía del interés general que aboga por la aplicación del régimen vigente en el momento en el que se otorgan. De otra, la seguridad jurídica del promotor que llevaría a inclinar la balanza del lado de la norma aplicable en la fecha de la solicitud.

En realidad, es la disposición que efectúa el cambio la que, en cada caso, debería ofrecer la respuesta mediante la previsión del correspondiente régimen

${ }^{12}$ En tal sentido, y entre otras, Sentencias del Tribunal Supremo de 28 de marzo de 2006 (RJ 1115) o 26 de junio de 2006 (RJ 3974).

13 Así lo establece el artículo 7.4 de la Directiva 2009/72, de 13 de julio, sobre normas comunes para el mercado interior de la electricidad. 
transitorio. De esta forma, la duda solo surgiría en los supuestos en los que no exista régimen transitorio o este se considere insuficiente. Aún reconociendo la dificultad del tema y la necesidad de atender a cada una de las situaciones que puedan presentarse, quizá, en términos generales, deba sostenerse que la norma aplicable ha de ser la vigente en la fecha de concesión de la autorización, sin perjuicio de los posibles derechos que ante el cambio normativo puedan asistir a los interesados. Y es que, con las debidas cautelas desde luego, podría entenderse que estos interesados serían titulares de unas expectativas que coinciden, no con un derecho in fieri, concepto tradicional de la figura ${ }^{14}$, sino con el simple deseo de estabilidad de la norma, de mantenimiento de un determinado régimen jurídico en base al cual se han tomado decisiones y se han emprendido actuaciones de tal forma que si la norma cambia bruscamente pueden sufrirse evidentes perjuicios. La protección de estas expectativas puede encontrar fundamento, como han reconocido el Tribunal Superior de Justicia de las Comunidades europeas, el Tribunal Constitucional y el Tribunal Supremo, en el principio de seguridad jurídica concebido en términos de estabilidad de la norma y de previsibilidad de su alteración; esto es, en términos de confianza legítima ${ }^{15}$.

\section{LOS PROCEDIMIENTOS DE AUTORIZAGIÓN: GARACTERÍS- TICAS BÁSICAS Y PROBLEMAS FUNDAMENTALES}

Debe lógicamente diferenciarse entre las distintas autorizaciones que, como hemos visto, concurren en la construcción y puesta funcionamiento de instalaciones de producción eléctrica. He de advertir, además, que no pretendo la exposición completa y acabada de los diferentes procedimientos sino, tan sólo, dejar constancia de sus notas más características y, en su caso, de los problemas y dudas que suscita su regulación ${ }^{16}$.

14 Vid. ESCRIBANO COLLADO, P. "Voz expectativa", Enciclopedia furídica Civitas, Vol. II, op. cit., pág. 2997.

${ }^{15}$ Vid. BARRERO RODRÍGUEZ, C. "El respeto a los derechos adquiridos", Documentación Administrativa, núm. 263-4, 2002, en particular, págs. 162-178.

Con posterioridad a esa fecha, pueden verse las interesantes Sentencias del Tribunal Supremo de 14 de junio de 2010 (RJ 5668, 5669 y 5670, respectivamente).

${ }^{16}$ Estamos además ante una materia que ha recibido escasa atención por la doctrina. Entre los análisis más completos se encuentra el de NEBREDA PÉREZ, J.M., Distribución eléctrica. Concurrencia de disciplinas jurídicas, Thomson-Aranzadi, Navarra, 2003. 


\section{El permiso de acceso y conexión a las redes. La atribu- ción de funciones públicas a entidades privadas.}
A. La necesidad de procedimientos de priorización.

El acceso y conexión a la red de transporte está regulado en el Título IV del RD 1955/2000, de aplicación supletoria en Andalucía ${ }^{17}$. Esta Comunidad Autónoma cuenta, no obstante, con dos importantes normas en la materia: la Orden de la entonces Consejería de Innovación, Ciencia y Empresa de 8 de julio de 2005 de instalaciones de generación de energía eléctrica en régimen especial gestionable y el Decreto 50/2008, de 19 de febrero, de energía solar fotovoltaica, recientemente modificado por el Decreto 9/2011, de 18 de enero, sobre procedimientos administrativos en materia de industria y energía. Cabe, no obstante, señalar que el contenido de las normas andaluzas apenas difiere del establecido en la disposición estatal.

No creo que tenga interés la exposición detallada del procedimiento que conduce a la obtención de este permiso, requisito previo indispensable para la obtención de la autorización de la instalación ${ }^{18}$. Centraré mi atención en los que, a mi juicio, constituyen los aspectos de mayor interés.

Aunque la producción de energía eléctrica se ha liberalizado, el transporte y la distribución mantienen, en términos del artículo 11.2 de la LSE, el "carácter de actividades reguladas, cuyo régimen económico y de funcionamiento se ajustará a lo previsto en la presente Ley"19. Se garantiza así "el acceso de terceros a las redes de transporte y distribución", al tiempo que se reconoce la posible restricción motivada del derecho si la red no dispone "de la capacidad necesaria" 20 . De hecho, la capacidad limitada de la red, inferior en muchos casos a la demanda existente, es la que explica y justifica que la obtención de los permisos de acceso vaya, por lo general, precedida de procedimientos previos destinados a su distribución y que han de estar basados en

${ }^{17}$ Sobre este régimen puede consultarse el estudio de GIMÉNEZ CERVANTES, J. "El régimen jurídico-administrativo de las energías renovables" (Tratado de energías renovables, Vol I, BECKER, F., CAZORLA, L.M y J. MARTÍNEZ-SIMANCAS (Dir.), op. cit., págs. 95-7).

18 Artículos 28.3 de la LSE y 5 del RD 661/2007, de 25 de mayo.

${ }^{19}$ Vid. sobre el particular, BACIGALUPO SAGGESE, M., "Electricidad, servicio público y mercado", AAVV Tratado de regulación del sector eléctrico, T. I, op. cit., págs. 103-5.

${ }^{20}$ Vid. artículos 11.2 y 38.2 de la LSE y 52 del RD 1955/2000, de 1 de diciembre. 
principios de objetividad, transparencia y no discriminación ${ }^{21}$. Es claro que estos procedimientos de priorización aportan seguridad y racionalidad en el proceso de implantación de nuevas instalaciones, aunque no contribuyen, desde luego, a la simplificación y agilización administrativa que el mercado parece demandar. Cabe reparar también, desde una perspectiva distinta, en cómo por esta vía la prioridad normativa en favor de las energías renovables puede quedar considerablemente mermada al depender, en definitiva, de los límites propios de la actividad de transporte.

Andalucía cuenta con una regulación de estos procedimientos que varia en función de que la instalación de generación eléctrica para la que se solicita el permiso vaya a emplear tecnologías gestionables o tecnologías no gestionables. Se consideran gestionables "aquellas unidades de generación que su producción no está condicionada en el recurso energético primario por factores fisicos no controlables y que, debido a ello, pueden proporcionar un nivel de potencia suficientemente garantizado cuando lo requiera el Operador del Sistema, para garantizar el funcionamiento seguro del sistema eléctrico"22. Son la termosolar, minihidráulica, biomasa o cogeneración. Las tecnologías no gestionables, de otra parte, son "aquellas cuya fuente primaria no es controlable ni almacenable y cuyas plantas de producción asociadas carecen de la posibilidad de realizar un control de la producción siguiendo instrucciones del operador del sistema sin incurrir en un vertido de energía primaria, o bien la firmeza de la previsión de producción futura no es suficiente para que pueda considerarse como programa" 23 . Pertenecen a esta categoría las tecnologías que utilizan como energía primaria la solar, la eólica o las centrales hidroeléctricas de determinada potencia ${ }^{24}$. Hay que tener en cuenta, no obstante que, en aplicación del Apartado $3^{\circ}$ del Anexo XI del RD 661/2007, el Operador del Sistema, esto es, Red Eléctrica española (REE), puede otorgar, previa una valoración específica, la calificación de gestionable a instalaciones con tecnología no gestionable.

${ }^{21}$ BACIGALUPO SAGGESE, M. se ha manifestado en términos críticos con estos procedimientos autonómicos que, a su juicio, pueden afectar a diferentes principios básicos del ordenamiento en la materia ("La distribución de competencias entre el Estado y las Comunidades Autónomas en materia de energías renovables", op. cit., págs. 62-3).

22 Definición tomada del artículo 2 de la Orden de 8 de julio de 2005.

${ }^{23}$ En términos del Apartado $3^{\circ}$ del Anexo XI del RD 661/2007 que reitera el "Plan de acción de energías renovables (PANER) 2011-2020, aprobado en julio de 2010 (págs. 100-1).

24 Apartado $3^{\circ}$ del Anexo XI del RD 661/2007. 


\section{B. Las tecnologías gestionables.}

La Orden de 8 de julio de 2005, parcialmente modificada por la Resolución de 30 de octubre de 2007 y por la Orden de 29 de febrero de 2008, regula la tramitación de las instalaciones de generación eléctrica en régimen especial gestionable y los procedimientos de acceso y conexión a las redes en términos de los que cabe destacar, por encima de cualquier otra nota, la atribución de funciones públicas a entidades privadas, lo que, como veremos, suscita algunos problemas importantes en relación, sobre todo, con las posibilidades de defensa de los interesados ${ }^{25}$.

\section{a) El procedimiento y la resolución de priorización.}

El promotor ha de solicitar y obtener del gestor de la red a la que desee conectarse, la "Certificación de Gestionable". Si la solicitud recae sobre plantas de generación de las consideradas, en principio, no gestionables, el gestor de la red dará traslado de la solicitud a REE para que en el plazo de un mes emita el correspondiente "informe de gestionabilidad". El gestor de la red notificará la "Certificación de Planta Gestionable" al promotor y a la Delegación Provincial de la Consejería competente. En el mes siguiente, el promotor, de nuevo ante el gestor de la red, deberá solicitar la conexión "de conformidad con lo establecido en el RD 1955/2000, de 1 de diciembre, proponiendo el punto y condiciones básicas" de la conexión. Si transcurren tres meses desde la obtención de esa certificación sin que su titular haya solicitado el acceso, la Delegación Provincial podrá declararle "decaído en el procedimiento de priorización en el acceso a red, procediendo a la devolución del aval" correspondiente $^{26}$. Resulta de interés advertir la falta de concordancia existente entre el plazo de un mes establecido para la solicitud del punto de acceso y el de tres previsto, de conformidad con el artículo 92.1 de la Ley 30/1992 (LRJ-PAC), para dar por concluido el procedimiento en caso de inactividad del promotor. Una disparidad de la que, en último término, resulta la existencia de un plazo de dos meses en el que ni la Administración ni el promotor pueden hacer nada.

${ }^{25}$ En relación con este fenómeno en este ámbito de la energía puede consultarse el artículo de LÓPEZ DE CASTRO GARCÍA-MORATO, L. "Funciones públicas ejercidas por particulares: El caso del Operador del sistema eléctrico según la Ley 54/1997", Revista Andaluza de Administración Pública, núm. 75, 2009, págs. 139-178.

Con un carácter más general, me remito a la fundamental monografía de CARRILLO DONAIRE, J.A., El Derecho de la seguridady de la calidad industrial, Marcial Pons, Madrid, 2000, en particular, págs. 21-83.

${ }^{26}$ Vid. artículos 4 y 5.1 y 2. 
Recibida la solicitud de conexión, el gestor de la red realizará los estudios de viabilidad correspondiente, solicitando informe a REE si las instalaciones o agrupaciones de instalaciones a conectar en la red de distribución superan los $10 \mathrm{MW}^{27}$. Los estudios de viabilidad se realizan trimestralmente. En el mes siguiente al vencimiento de cada trimestre del año natural, el gestor de la red remitirá a la Delegación Provincial o a la Dirección General ${ }^{28}$, los estudios de acceso junto con los expedientes de cada solicitante. Igualmente, y en su caso, deberá informar sobre "la concurrencia de solicitudes en un mismo elemento de la red, capacidad de evacuación disponible" y si las solicitudes la superan o no ${ }^{29}$.

La Delegación Provincial o la Dirección General resolverán priorizando el acceso de las peticiones que se hayan producido en el trimestre de referencia ${ }^{30}$. En el caso de concurrencia de solicitudes "en el mismo nudo u otro próximo que afecte eléctricamente, superándose la capacidad del mismo", la Dirección General, salvo acuerdo alcanzado por todos los interesados, dictará "resolución de priorización"31 de acuerdo con los parámetros de valoración establecidos en el artículo 7.2.c) de la Orden que detalla además cómo se han de acreditar y la puntuación que pueden merecer en un claro y loable intento de reducir en lo posible la discrecionalidad técnica existente en este ámbito ${ }^{32}$. Esta resolución se ha de dictar y notificar a los solicitantes, distribuidor de zona y gestor de la red de transporte en el plazo de tres meses "contados a partir de la notificación de la solicitud de documentación complementaria precisada para la priorización" 33 .

${ }^{27}$ El plazo de emisión de este informe es de un mes.

${ }^{28}$ Deberá hacerlo a la Dirección General "en el caso de que las solicitudes de acceso en un elemento de red superen el ámbito provincial" (artículo 6.2).

${ }^{29}$ Vid. artículo 6.

${ }^{30} \mathrm{El}$ contenido de la resolución aparece en el artículo 7.1.

${ }^{31}$ Con carácter previo, otorgará a los solicitantes un plazo de dos meses para que aporten la documentación complementaria que determina el artículo 7.2.a) de la Orden. Entre ella figura la que acredita las autorizaciones y licencias ya concedidas, la existencia de instalaciones con inscripción definitiva en el régimen especial, el capital social del promotor, la disponibilidad de los terrenos o equipos generadores y la garantía de financiación del proyecto.

32 Estos parámetros son: "madurez administrativa del proyecto", "capacidad técnica y económica de los promotores o titulares y viabilidad técnica del proyecto" y "nuevos planes industriales".

${ }^{33}$ Es la regla establecida por el artículo 7.2.e) de la Orden y que coincide con la que mas tarde recogió el artículo 31 de la Ley 2/2007, de 27 de marzo, de fomento de las energías renovables y de ahorro y eficiencia energética de Andalucía. 
El promotor podrá desistir de su solicitud si el punto de acceso que se le otorga está ubicado en un lugar diferente al que propuso o dispone de una capacidad inferior a la deseada, en cuyo caso se procederá a un reparto proporcional de la potencia a la que se renuncia ${ }^{34}$. Si, por el contrario, está conforme con la resolución deberá presentar, en el plazo de dos meses, "ante la empresa transportista o distribuidora propietaria de la red en dicho punto, el proyecto básico de instalación y su programa de ejecución" y "ante el órgano administrativo competente, la solicitud de autorización administrativa de la instalación eléctrica de producción"35.

\section{b) La vigencia del punto de conexión y su prórroga. Una regulación anómala desde las categorías propias del Derecho Administrativo.}

La vigencia del punto de conexión concedido es de un año contado a partir de la notificación de la resolución de aprobación del proyecto. La Orden de 2005 reconoce, no obstante, la posibilidad de una prórroga ordinaria y, en su caso, otra extraordinaria, ambas por un periodo máximo de un año, por las razones que, respectivamente, determinan los apartados 2 y 3 de su artículo 9 .

Las prórrogas las ha de conceder o denegar el gestor de la red de transporte o compañía distribuidora previo informe favorable de la Dirección General competente en materia de energía. Esto es, resuelve, lo que no deja de ser llamativo, una entidad privada con base en el informe preceptivo y vinculante de un órgano administrativo. Esta atribución de una función pública a un sujeto privado plantea, entre otras cuestiones de interés, la relativa a la vía de impugnación procedente contra sus decisiones o, lo que es lo mismo, cómo puede, en su caso, oponerse el interesado a la resolución del gestor de la red que le deniega la prórroga solicitada. La norma que comentamos no contiene ninguna previsión al respecto, por lo que la respuesta habrá de buscarse en lo dispuesto con carácter general en el ordenamiento vigente. Así, y de una parte, debe destacarse que la resolución de los conflictos derivados del derecho de acceso viene atribuida a la Comisión nacional de la Energía por el artículo 53.8 del RD 1955/2000, de aplicación supletoria en Andalucía ${ }^{36}$. De otra parte, cabe

\footnotetext{
${ }^{34}$ El plazo establecido para el desistimiento por el artículo 7.3 es de un mes.

35 Artículo 8. El incumplimiento de ese plazo de dos meses da lugar a la pérdida de la priorización realizada por la Administración, procediéndose al reparto proporcional de la potencia cancelada entre los diferentes solicitantes en concurrencia.

36 Vid. también el artículo 15 del RD 1339/1999, de 31 de julio, por el que se aprueba el Reglamento de la Comisión nacional de la energía.

M. BACIGALUPO SAGGESE, en términos a los que me remito, se ha referido a la com-
} 
defender también la posible impugnación del informe de la Dirección General al tratarse, en aplicación del artículo 107.1 de la LRJ-PAC, de un acto de trámite recurrible en la medida en que decide directamente sobre el fondo del asunto.

\section{Las tecnologías no gestionables. La energía eólica.}

Recordemos que estas tecnologías son "aquellas cuya fuente primaria no es controlable ni almacenable y cuyas plantas de producción asociadas carecen de la posibilidad de realizar un control de la producción siguiendo instrucciones del operador del sistema sin incurrir en un vertido de energía primaria, o bien la firmeza de la previsión de producción futura no es suficiente para que pueda considerarse como programa". Pertenecen a esta categoría "las centrales de producción de electricidad que utilicen como energía primaria alguna de las siguientes: solar, eólica, geotérmica, maremotriz, olas, rocas calientes y secas, oceanotérmica y corrientes marinas, así como los generadores hidráulicos fluyentes integrados de potencia inferior o igual a $50 \mathrm{MW}$, salvo valoración específica de gestionable de una planta generadora a realizar por el operador del sistema, con la consecuente aplicación de los requisitos o condicionantes asociados a dicha condición" $" 37$.

El Derecho de Andalucía cuenta con normas propias para las dos fuentes de energía de esta clase más desarrolladas: la eólica y la solar fotovoltaica. Comencemos por la primera.

Los permisos de acceso a las redes para instalaciones de generación que utilizan como energía primaria la eólica, han exigido también procedimientos de priorización ante la existencia de una demanda muy superior a la permitida por la red. Hasta la fecha se han celebrado dos concursos. Uno primero que se resolvió por la Orden 20/2002 y uno segundo en cumplimiento de la Orden de la entonces Consejería de Innovación, Ciencia y Empresa de 29 de febrero de 2008.

petencia de la Comisión Nacional de la Energía sobre los conflictos de acceso a las redes, destacando la colisión normativa que en este ámbito se suscita entre la LSE y la norma reguladora de este organismo. ("La distribución de competencias entre el Estado y las Comunidades Autónomas en materia de energías renovables", op.cit., págs. 58-60).

Sobre el alcance de esta competencia puede verse también la Sentencia del Tribunal Supremo de 8 de octubre de 2008 (RJ 5635).

${ }^{37}$ Apartado $3^{\circ}$ del Anexo XI del RD 661/2007. 
El procedimiento establecido por esta última Orden no difiere sustancialmente del previsto en la de 2005 para las tecnologías gestionables. La resolución de priorización se atribuye a la Dirección General competente en materia de energía previo informe conjunto del distribuidor de zona y gestor de la red. La vigencia del punto de conexión es de un año susceptible de prórrogas por los mismos plazos y causas que las establecidas por la Orden reguladora de las tecnologías gestionables. La competencia para acordarla se otorga igualmente al gestor de la red de transporte previo informe favorable de la citada Dirección General. Me remito, por consiguiente, a cuanto fue expuesto en el apartado anterior.

D. Las tecnologías no gestionables. La energía solar fotovoltaica.

a) El acceso y conexión a la red. Los problemas que suscita.

El procedimiento de acceso y conexión a la red de las instalaciones que utilizan esta clase de energía está regulado en el Decreto 50/2008, de 19 de febrero, recientemente modificado por el Decreto 9/2011, de 18 de enero. Las instalaciones conectadas a la red se clasifican por el artículo 4 en dos categorías, las clases 1 y 2. A la primera pertenecen "las instalaciones de potencia nominal no superior a 100KW" cuya "conexión a la red de distribución se efectúe en baja tensión". A la segunda, "las instalaciones de cualquier potencia" cuya "conexión a la red se efectúa en media o alta tensión". La regulación de la solicitud del punto de acceso difiere según se trate de instalaciones de una u otra clase.

El promotor, para el caso de instalaciones de clase 1, debe solicitar el punto de acceso y conexión a la empresa distribuidora de energía eléctrica que, como dispone el artículo 9.1, "tendrá que facilitar la información solicitada en el plazo de un mes, desde la recepción de la correspondiente solicitud, siempre que la evacuación de la energía generada no requiera ampliación de la red de distribución"38. A pesar de la ambigüedad de la expresión empleada por el precepto: "proporcionar la información solicitada", lo que, quizá, haga la empresa distribuidora es resolver ${ }^{39}$. Si es así, el punto de acceso lo otorgaría una entidad

\footnotetext{
${ }^{38}$ Casos en los que, al igual que en las agrupaciones solares, se estará a lo establecido en el artículo 16 .

${ }^{39}$ Es lo que resulta del RD 1663/2000, de 29 de septiembre, de conexión de instalaciones fotovoltáicas a la red de baja tensión que en su artículo 4.1 determina que "la empresa distribuidora notificará al solicitante su propuesta relativa a las condiciones de conexión". Con mayor claridad, la Instrucción de la Dirección General de Industria, energía y minas de Andalucía de
} 
privada en lo que constituye un nuevo supuesto de ejercicio de funciones públicas por particulares. Desde luego, cabe lamentar que la norma recién promulgada, el Decreto 9/2011, no haya precisado el contenido de una disposición que puede generar dudas en su aplicación.

El punto de acceso y condiciones de conexión se solicitará, si se trata de instalaciones de clase 2, a la empresa distribuidora de acuerdo con lo establecido en el Título IV del RD 1955/2000. El gestor de la red de distribución de la zona dispone de quince días de plazo para comunicar al solicitante "la existencia o no de capacidad suficiente de la red de distribución". Si se habían solicitado ya las condiciones de conexión, el plazo será de un mes ${ }^{40}$.

En los supuestos en los que la empresa distribuidora no notifique su decisión en los tiempos establecidos, el interesado, ya sea en una instalación de clase 1 o 2, puede solicitar la intervención de la Delegación Provincial correspondiente que recabará los datos a la empresa distribuidora para que los aporte en un plazo de quince días ${ }^{41}$. Ahora bien, lo que la norma no determina es cuales son las garantías de los interesados ante una posible situación de inactividad de la empresa. Si aclara, sin embargo, el órgano competente para la resolución de las discrepancias entre el solicitante y la empresa distribuidora sobre el punto de acceso y las condiciones de conexión: las Delegaciones Provinciales o la Dirección General a excepción de los supuestos asignados a la Comisión Nacional de la Energía ${ }^{42}$. Resulta de interés reparar en cómo estos órganos se convierten en instancia resolutoria de conflictos entre un particular y una entidad privada que actúa ejerciendo funciones públicas. Y es que al margen de los términos que la disposición pueda emplear, lo que, en verdad, se produce en estos casos es una impugnación por el interesado del acto de la empresa distribuidora que le deniega el permiso de acceso o se lo otorga en condiciones distintas a las solicitadas. Esta impugnación puede plantear, no obstante, algunas dudas que la norma no resuelve. De una parte, la determinación de las reglas que han de regir su tramitación. De otra, el sentido, que parece claro que ha de ser negativo ${ }^{43}$, que deba otorgarse a la falta de res-

21 de enero de 2004, sobre el procedimiento de puesta en servicio de las instalaciones fotovoltaicas conectadas a red, indica en su Apartado 2.2 que "la empresa distribuidora determinará el punto y las condiciones de conexión ....".

${ }^{40}$ Artículo 9.2.

${ }^{41} \mathrm{El}$ incumplimiento de esta obligación puede constituir infracción administrativo en aplicación de la LSE, según establece el artículo 9.6 del propio Decreto 50/2008.

42 Artículo 9.7.

${ }^{43}$ Artículo 43.1 de la LRJ-PAC. 
puesta por la Administración en los tres meses establecidos al efecto. No deja por ello de sorprender que la reciente reforma del Decreto 50/2008 por el 9/20011 no haya aclarado unas cuestiones en las que se juegan garantías importantes de los administrados en sus relaciones con la Administración Pública.

\section{b) La vigencia del punto de conexión y sus prórrogas. Las dudas y soluciones del Decreto 9/2011.}

Obtenido el punto de conexión, el interesado deberá solicitar la autorización administrativa y proyecto técnico en el plazo máximo de un mes ${ }^{44}$. La vigencia del punto de conexión es de un año "a partir de la fecha de notificación de la resolución de aprobación del proyecto" 45 . Este plazo es susceptible de una prórroga ordinaria, así como de prórrogas extraordinarias por periodos que, en ningún caso, podrán superar el año ${ }^{46}$. Interesa destacar que la posibilidad de varias prórrogas extraordinarias ha sido introducida por el Decreto 9/2011 que amplia así las facultades de disposición de la Administración para conceder aquellas ampliaciones del plazo originario que estime pertinentes en función de las circunstancias concurrentes. Una regla probablemente más ajustada a la realidad que la establecida por el Decreto 50/2008 que en su originaria redacción tan sólo permitía una prórroga extraordinaria. Tampoco debe pasar inadvertido el hecho de que en el nuevo artículo 10 han desaparecido las condiciones que, antes de su modificación de 2011, actuaban como presupuesto determinante de la prórroga extraordinaria: que "la instalación generadora esté ejecutada en el 50\% en términos de instalación de módulos fotovoltaicos y, en términos de inversión, efectivamente facturada, o por retraso

${ }^{44}$ Artículo 11.1.

${ }^{45}$ Es lo que dispone el artículo 9.4 del Decreto 50/2008 tras la reforma del Decreto 9/2011 que cuenta el plazo a partir de "la fecha de la notificación de la resolución de aprobación del proyecto" y no, como establecía el precepto en su redacción originaria, desde "la resolución de aprobación del proyecto". De esta forma, los eventuales retrasos en los que la Administración pueda incurrir en su deber de notificación no repercutirán sobre los interesados.

${ }^{46}$ El Decreto 9/2011 ha introducido un nuevo apartado en el artículo 10, el 6, a los efectos de reconocer la suspensión tanto de la vigencia del punto de conexión como de los plazos de las prórrogas "desde el momento en que quede acreditada documentalmente la participación efectiva en el registro de preasignación establecido en el artículo 6 del Real Decreto 1578/2008, de 26 de septiembre, por el tiempo en que permanezca en esta situación, reanudándose el cómputo de dichos plazos a partir del día siguiente en que se notifique al interesado la resolución de la convocatoria prevista, o bien se de publicidad a la misma por el órgano competente de la Administración General del Estado". 
justificado en la construcción del edificio en el que se ubiquen las instalaciones fotovoltaicas", optándose por una fórmula mucho más abierta. La prórroga, en expresión del reformado artículo 10.2, se concederá, en su caso, "tras la valoración concreta de las circunstancias puestas de manifiesto en la solicitud realizada por el promotor, así como del cumplimiento de los trámites necesarios dentro del expediente". También el apartado primero del precepto flexibiliza las causas que pueden justificar la prórroga ordinaria al determinar, frente al elenco de supuestos tasados de la disposición anterior ${ }^{47}$, que para su concesión se tomarán "en consideración las actuaciones previas realizadas por el promotor tendentes a la ejecución material de la instalación, tales como la disponibilidad de la totalidad de los terrenos o emplazamientos, los bienes de equipo, así como el cumplimiento de los trámites necesarios para la obtención de los correspondientes permisos y autorizaciones ante otras administraciones".

La prórroga, en términos del artículo 10.1, "se hará efectiva por el gestor de la red eléctrica o empresa distribuidora a la que se conectará la planta generadora, previo informe preceptivo y vinculante del órgano competente indicado en el artículo 5", esto es, de las Delegaciones Provinciales o de la Dirección General. La regla es, por tanto, la misma que ya hemos comentado para las instalaciones que se sirven de otras fuentes de energía primaria, lo que, en principio, nos eximiría de cualquier comentario. Ahora bien, debe observarse aquí como el Decreto 9/2011 sustituye la expresión del artículo 10.1 del Decreto $50 / 2008^{48}$ : la prórroga "se resolverá por el gestor de la red o empresa distribuidora" 49 , por otra que, quizá, no signifique exactamente lo mismo: la prórroga "se hará efectiva por el gestor de la red ...". Aunque no es fácil averiguar las razones que se esconden detrás de este cambio terminológico, resulta evidente que con la redacción actual se acentúa, si cabe, la idea de que quien resuelve realmente sobre las prórrogas es la Dirección General o la Delegación Provincial en ese informe preceptivo y vinculante que juega como presupuesto necesario y determinante de la decisión del gestor de la red o empresa distri-

\footnotetext{
${ }^{47}$ Artículo 10.1.b) del Decreto 50/2008 en su redacción originaria.

${ }^{48}$ La misma que figura en el artículo 9.2 de la Orden de 8 de julio de 2005.

${ }^{49}$ Interesa señalar que en el dictamen emitido por el Consejo Consultivo de Andalucía en el procedimiento de elaboración de esta norma, el Dictamen 100/2008, de 13 de febrero, no existe ningún pronunciamiento que pueda contribuir a aclarar el significado de este importante precepto. En realidad, el dictamen tan solo formuló al texto sometido a su enjuiciamiento objeciones y observaciones de técnica normativa.
} 
buidora. La expresión "hará efectiva" empleada por el artículo 10.1 del Decreto 50/2008 tras su reciente modificación, parece aludir a la simple ejecución de una decisión previamente tomada por otro sujeto.

Cabe finalmente llamar la atención sobre la regla, introducida igualmente en la reforma de enero de 2011, que determina que "las solicitudes de prórroga del punto de conexión se presentarán ante el órgano competente para otorgar dicha prórroga...”. Este nuevo apartado del artículo 10, necesario en la medida en que viene a suplir una laguna de la norma anterior, plantea, sin embargo, una duda importante: la relativa a la propia determinación del órgano al que se refiere, toda vez que en la disposición no aparece ningún órgano al que se atribuya esa cualidad de "órgano competente". ¿Acaso el "órgano competente" al que alude el artículo 10.5 es el que hace efectiva la prórroga de acuerdo con el 10.1? Si es así, la norma habría incurrido en una notable imprecisión toda vez que el gestor de la red o empresa distribuidora a los que se refiere este último apartado no merecen propiamente la condición de órgano. El "órgano competente", ¿es el que emite el informe que sirve de base a la decisión de quien hace "efectiva" la prórroga. Ante la indefinición del precepto parece lógico pensar que el interesado deberá dirigirse a quien, en última instancia, ha de hacer realidad su derecho a una ampliación del plazo originario, el gestor de la red o empresa distribuidora, sin perjuicio de que pueda presentar también su solicitud ante esos órganos administrativos que son los que, en verdad, deciden con su informe. Esta es, de hecho, la regla que establece el artículo 9.2 de la Orden de 8 de julio de 2005 que dispone que la solicitud de prórroga "deberá presentarse simultáneamente ante el gestor de la red de transporte o compañía distribuidora en materia de energía y la Dirección General con competencia en materia de energía".

En definitiva, es claro que la reforma del Decreto 50/2008 por el 9/2011 ha adaptado la regulación de las prórrogas de los puntos de conexión a la situación real de este mercado y ofrecido respuesta a algunas de las lagunas detectadas en su aplicación. Cabe lamentar, sin embargo, su falta de precisión en algunos aspectos y las dudas interpretativas que, por consiguiente, puede generar en su aplicación.

\section{La autorización para la construcción y puesta en funcio- namiento de las instalaciones de producción.}

Andalucía no cuenta con una regulación general de estos procedimientos, lo que determina la aplicación supletoria del RD 1955/2000. Su normativa es, 
en efecto, muy incompleta. La Ley de Fomento de las energías renovables tan solo dedica dos preceptos al procedimiento, los artículos 30 y $31^{50}$. El primero señala que se regirán por "los principios de simplificación y agilización administrativa", incorporarán "las tecnologías de la información y la comunicación para facilitar su tramitación a través de medios telemáticos y electrónicos" y se "articularán los instrumentos de coordinación necesarios con otras Administraciones Públicas para la consecución de un servicio unificado de atención al ciudadano". El artículo 31, de otra parte, establece los plazos de duración de los procedimientos y el sentido de la falta de resolución expresa. Las numerosas disposiciones de inferior rango dictadas hasta la fecha prescinden de la regulación de este procedimiento a excepción del Decreto 50/2008, para las instalaciones fotovoltaicas, cuyas reglas, además, no difieren de las establecidas en la norma estatal. Centraremos, pues, nuestra atención en la tramitación prevista en el Título VII del citado RD 1955/2000 con aquellas particularidades que, en su caso, pueda ofrecer el Derecho de Andalucía.

Recordemos que la construcción y explotación de instalaciones eléctricas requiere varias resoluciones administrativas: a) La autorización administrativa del anteproyecto de la instalación; b) La aprobación del proyecto de ejecución que, en términos del artículo 115.b), "se refiere al proyecto concreto de la instalación y permite a su titular la construcción o establecimiento de la misma"; y c) La autorización de explotación que, una vez ejecutado el proyecto, faculta a su titular, como dispone la letra c) del mismo precepto, a "poner en tensión las instalaciones y proceder a su explotación comercial". Hay que advertir, no obstante, que las dos primeras resoluciones pueden tramitarse y obtenerse, como establece el propio precepto, de "manera consecutiva, coetánea o conjunta". Tampoco conviene olvidar, como igualmente hemos señalado, que la autorización energética se otorga "sin perjuicio de las concesiones y autorizaciones que sean necesarias, de acuerdo con otras disposiciones que resulten aplicables y en especial las relativas a la ordenación del territorio y el medio ambiente".

${ }^{50}$ Y ello a pesar de que el Dictamen 3/2006, del Consejo Económico y Social de Andalucía al Anteproyecto de Ley insistiera en la importancia que la futura norma había de tener en la consecución de procedimientos administrativos más ágiles y racionales y "un mayor grado de coordinación entre los diferentes organismos administrativos implicados en los procedimientos de concesión de los permisos necesarios para la producción de energía y la instalación de nuevas plantas generadoras ..". 
A. La autorización del anteproyecto de instalación.

Antes de examinar su procedimiento, interesa señalar que en Andalucía esta autorización no será necesaria, en aplicación del artículo 12.6 de la Ley de Fomento de las energías renovables, cuando las "actuaciones contempladas en programas territoriales de energías renovables" hayan "sido desarrolladas a su vez mediante Planes Especiales de Ordenación". En estos casos, será suficiente con el proyecto de ejecución.

\section{a) La solicitud: El informe de compatibilidad urbanística.}

El solicitante ha de reunir los requisitos exigidos por el artículo 70 de la LRJ-PAC y acreditar su capacidad legal, técnica y económico-financiera para la realización del proyecto en los términos establecidos por el artículo 121 del RD 1955/2000. La solicitud ha de ir acompañada de un anteproyecto de la instalación con el contenido que determina el artículo 123 de la norma: a) Una memoria ${ }^{51}$; b) Los planos de la instalación a escala mínima de 1:50.000; c) Presupuesto estimado; d) Las separatas para las Administraciones Públicas, organismos y, en su caso, empresas de servicios públicos o de servicios interés general con bienes o servicios a su cargo afectados por la instalación; y e) Los demás datos que la Administración encargada de tramitar el expediente estime oportuno reclamar ${ }^{52}$.

El artículo 12.2 de la Ley de Fomento de las energías renovables de Andalucía exige, además, que junto con la solicitud se presente "un anexo que describa las determinaciones del planeamiento urbanístico de aplicación y el análisis de su cumplimiento", así como "un informe de compatibilidad urbanística emitido por el Ayuntamiento en cuyo municipio se pretenda la actuación" ${ }^{33}$. Esta previsión, de cuyo buen sentido no cabe dudar en aras de una

${ }^{51} \mathrm{Su}$ contenido es muy heterogéneo aunque, en todo caso, de gran relevancia: la ubicación de la instalación, su objeto y sus características principales. El Tribunal Superior de Justicia de Castilla-León en tres Sentencias de 21 de octubre de 2005 (JUR 16295, 16299, 16308, de 2006) ha destacado la relevancia de este documento.

${ }^{52} \mathrm{El}$ artículo 11 del Decreto 50/2008, recientemente reformado por la norma de igual rango 9/2011, regula las solicitudes de instalaciones solares fotovoltaicas en Andalucía en términos muy parecidos a los de la disposición estatal.

${ }^{53}$ Esta misma exigencia figura en el artículo 11.1.f) del Decreto 50/2008 para las instalaciones solares fotovoltaicas. 
adecuada coordinación de los distintos títulos competenciales que concurren en las instalaciones de este tipo, plantea, algunas cuestiones de interés. Antes de adentrarnos en ellas, quizá interese señalar que este artículo 12.2 fue aprobado en los mismos términos en los que figuraba en el Proyecto de Ley aprobado por el Consejo de Gobierno ${ }^{54}$. Tampoco el Consejo Consultivo de Andalucía en su Dictamen 252/2006, de 28 de junio, al Anteproyecto de Ley efectúo comentario alguno sobre su contenido.

De entrada, cabe plantear si la exigencia del informe de compatibilidad urbanística del Ayuntamiento no hace perder buena parte de su sentido a ese anexo exigido al promotor en el que han de describirse "las determinaciones del planeamiento urbanístico de aplicación y el análisis de su cumplimiento". En efecto, ante la valoración efectuada por la propia Administración municipal poca significación ha de tener el examen que pueda realizar el interesado. Y es que aunque pueda pensarse, y es cierto, que sus consideraciones pueden ser importantes a los efectos de combatir las contrarias al proyecto formuladas por el Ayuntamiento, no cabe olvidar que su informe no excluye la licencia urbanística que el mismo Municipio ha de otorgar una vez concedida la autorización energética, licencia que difícilmente dará si ya manifestó su oposición a la actuación pretendida. En definitiva, no es aventurado pensar que ningún promotor se arriesgará a poner en marcha el complejo procedimiento de obtención de la autorización para una instalación energética, habiendo mostrado el Municipio reticencias a su proyecto, por más seguro que él pueda estar sobre su adecuación a la ordenación urbanística aplicable. Este anexo tendrá, sin duda, más valor a los efectos de facilitar la emisión del informe de la Consejería competente "en materia de urbanismo sobre la adecuación territorial y urbanística de la actuación propuesta" exigido, como hemos de ver, durante la tramitación del procedimiento ${ }^{55}$.

Especial interés suscita, desde otro punto de vista, la cuestión relativa a la naturaleza del informe de compatibilidad urbanística. Y es que, a pesar de su denominación, es dudoso que pueda ser considerado un auténtico informe. No estamos realmente ante la emisión del parecer que un órgano formula para

\footnotetext{
54 Vid. el entonces artículo 11.2 del Proyecto de Ley (Boletín oficial del Parlamento de Andalucía, VII Legislatura, núm. 515, de 26 de septiembre de 2006), precepto y apartado, además, para el que no se propuso ninguna enmienda (Boletín oficial del Parlamento de Andalucía, VII Legislatura, núm. 600, de 9 de febrero de 2007).

${ }^{55}$ Artículos 12.2 de la Ley de Energías renovables y 11.4.b) del Decreto 50/2008 sobre instalaciones solares fotovoltaicas.
} 
que sea tenido en cuenta por otro. Nos hallamos ante un pronunciamiento municipal que de ser contrario a la instalación proyectada, hace que pierda sentido la iniciación misma del procedimiento para la concesión de la autorización energética. De hecho, el artículo 11.4.d) del Decreto 50/2008 para las instalaciones solares fotovoltaicas subordina la solicitud del promotor a la obtención del "informe favorable de compatibilidad urbanística".

En el caso de que el informe de compatibilidad urbanística sea contrario a la actuación, el interesado podrá ejercitar las vías de impugnación que procedan ante el propio Municipio. Ello es claro para el caso de instalaciones solares fotovoltaicas toda vez que de acuerdo con el artículo 11.4.d) del Decreto 50/2008, el informe favorable del Ayuntamiento opera como presupuesto necesario para la solicitud de la autorización energética. Pero ello parece claro también en aplicación del artículo 12.2 de la Ley de Fomento de las Energías renovables que aunque no subordina la petición a ese previo pronunciamiento municipal favorable, dispone con carácter general que si alguno de los informes que el propio precepto y apartado recoge, entre otros el que nos ocupa, fuese contrario a la actuación pretendida, "la Consejería competente en materia de energía dictará resolución motivada poniendo fin al procedimiento y archivará las actuaciones". Estamos, por consiguiente, ante un pronunciamiento municipal que, a pesar de su denominación, decide sobre el fondo del asunto y es perfectamente recurrible en aplicación de las reglas generales que rigen la impugnación de los actos en nuestro Derecho. No obstante, y de acuerdo con lo establecido en ese mismo artículo 12.2, el promotor interesado podrá solicitar la autorización del anteproyecto de instalación y recurrir la resolución autonómica que ponga fin al procedimiento, aunque, desde luego, cuesta pensar que alguien vaya a pedir una autorización que sabe, porque así lo dispone la Ley, que no va a tramitarse ante la oposición municipal al proyecto.

En definitiva, la regulación de este informe no es suficientemente precisa lo que no contribuye, desde luego, a la consecución de esos deseados objetivos de simplificación y transparencia en un mercado ya de por sí complicado ante la multiplicidad de intereses concurrentes y la propia complejidad técnica de la materia.

\section{b) La tramitación del procedimiento. En particular la inclusión en él de las autorizaciones previstas por la legislación sectorial.}

El RD 1955/2000 y el Decreto de Andalucía 50/2008 para las instalaciones solares fotovoltaicas no regulan un procedimiento acabado, tan solo prevén unos trámites de obligado cumplimiento que habrán de insertarse en la 
estructura del procedimiento que la Administración ha de seguir en aplicación de las Leyes generales que rigen su actuación. Son los siguientes.

- Información pública.

La información pública es preceptiva en los procedimientos de autorización del anteproyecto de instalación. ${ }^{56}$. Simultáneamente a esta información pública se desarrollará la exigida por el procedimiento de prevención ambiental que resulte aplicable a la instalación proyectada ${ }^{57}$.

- Consulta a otras Administraciones.

El órgano competente para la tramitación del procedimiento remitirá, en cumplimiento del artículo 127 del RD 1955/2000, "una separata del anteproyecto, conteniendo las características generales de la instalación y la documentación cartográfica correspondiente y, en su caso, un documento de síntesis del estudio de impacto ambiental" a "las distintas Administraciones, organismos o, en su caso, empresas de servicio público o de servicios de interés general en la parte que la instalación pueda afectar a bienes y derechos a su cargo" para que "en un plazo de veinte días presten su conformidad u oposición a la autorización solicitada”. La norma, en garantía del principio de contradicción, prevé el traslado sucesivo de la respuesta de estas Administraciones y demás entidades a los interesados y viceversa al objeto de que puedan rebatir los argumentos de la parte contraria ${ }^{58}$. Lo que la norma, sin embargo, no indica es que pasa si finalmente esas Administraciones y demás instancias siguen planteando objeciones al anteproyecto. En aplicación del artículo 83.1 de la LRJ-PAC que

${ }^{56}$ De las alegaciones presentadas en este trámite, cuyo plazo es de veinte días, se dará traslado al peticionario para que en un plazo no superior a quince, manifieste lo que estime pertinente (artículos 125.1 y 126 del RD 1955/2000).

${ }^{57}$ Artículos 124 del RD 1955/2000 y 32.2 del Decreto de Andalucía 356/2010 que regula la autorización ambiental unificada.

${ }^{58}$ Así establece que si transcurrido el plazo de veinte días sin que esas Administraciones y entidades se hayan pronunciado, se les reiterará el requerimiento para que en diez días manifiesten su posición. En caso de no contestar se presumirá su conformidad con el anteproyecto.

Su respuesta será trasladada al solicitante para que "en el plazo de quince días preste su conformidad o formule los reparos que estime procedentes". En este último caso, volverá a requerírseles para que muestren su acuerdo o desacuerdo a lo manifestado por el interesado. Pasados quince días sin que se hayan pronunciado, "se entenderá la conformidad con la contestación efectuada por el peticionario". 
determina que "salvo disposición expresa en contrario, los informes no son vinculantes", puede entenderse que el órgano instructor del procedimiento valorará lo manifestado por este conjunto de entidades y decidirá, en su caso, si algunas de sus alegaciones deben ser atendidas.

En el caso de instalaciones solares fotovoltaicas, las reglas generales establecidas en el RD 1955/2000 se ven desplazadas por las específicamente dispuestas en el Decreto 50/2008. Esta norma no prevé la participación de las Administraciones y demás organismos previsiblemente afectados como trámite propio del procedimiento autorizatorio. La manifestación de su conformidad u oposición a la instalación en proyecto ha de de acompañar a la propia solicitud en cumplimiento de lo dispuesto en el artículo 11.1 d) y e). Es, por consiguiente, el promotor el que, con carácter previo a su petición, ha de identificar a las Administraciones y demás entidades que considere afectadas por la actuación que se propone, solicitarles su conformidad y, en el caso de que ésta no se produzca, incorporar a su solicitud las alegaciones que estime pertinentes en respuesta a las objeciones formuladas por esas instancias. Quizá, la solución de la norma estatal sea más acertada en la medida en que cabe presumir, en principio, que el órgano instructor del procedimiento se encuentra en mejor disposición que el promotor para valorar cuales son las entidades que deben emitir su parecer sobre el proyecto de instalación. En todo caso, y en aplicación de las reglas generales que rigen en el procedimiento administrativo, dicho órgano podrá solicitar cuantos informes estime procedentes para la resolución.

- El informe sobre "la adecuación territorial o urbanística de la actuación propuesta”.

El artículo 12.2 de la Ley de Fomento de las energías renovables exige que en estos procedimientos informe "la Consejería competente en materia de urbanismo sobre la adecuación territorial o urbanística de la actuación propuesta". Estamos ante un informe preceptivo y vinculante como resulta de los claros y rotundos términos que el precepto emplea para el caso de que sea negativo: "la Consejería competente en materia de energía dictará resolución motivada poniendo fin al procedimiento y archivará las actuaciones". El Decreto 50/2008 para las instalaciones solares fotovoltaicas lo califica expresamente en su artículo 11.4.c) de "informe vinculante"59.

${ }^{59}$ Una calificación, por cierto, que no guarda quizá la debida coherencia con lo establecido en la letra b) del mismo precepto y apartado que dispone que si transcurre el plazo de emisión del informe, treinta días, sin haberse producido, "se continuará el procedimiento de autorización administrativa". En cualquier caso, la resolución no podrá producirse en tanto este informe no se haya emitido. 
La motivación, como exige el citado artículo 12.2, de la resolución que ponga fin al procedimiento quedará satisfecha, en estos casos, con la remisión al informe negativo. Ha de considerarse, de otra parte, que este informe constituye un acto de trámite susceptible de impugnación independiente de acuerdo con lo dispuesto en el artículo 107.1 de la LRJ-PAC. Igualmente, y en aplicación de las reglas generales que rigen la impugnación de los actos, el interesado podrá recurrir la resolución de la Consejería competente en materia de energía en la que se ponga fin al procedimiento con archivo de las actuaciones.

- Autorización del anteproyecto de instalación y licencia ambiental.

Los condicionantes medioambientales de la política energética son evidentes. De hecho, no es infrecuente que los proyectos de nuevas instalaciones de generación eléctrica provoquen la movilización de asociaciones y grupos de defensa de la naturaleza preocupados por el posible impacto negativo de estas actuaciones en el paisaje y en la preservación de los valores naturales. La propia jurisprudencia, en relación fundamentalmente con las instalaciones eólicas, nos da cuenta de hasta que punto puede, en muchos casos, resultar difícil armonizar la garantía del suministro de energía eléctrica con el derecho constitucional a un medio ambiente adecuado ${ }^{60}$. Un conflicto que, en términos de la Sentencia del Tribunal Supremo de 26 de mayo de $2009^{61}$ recogidos por otras muchas, "debe ser resuelto de conformidad con la norma que reconozca preferencia a un bien o interés sobre otro, si es que la protección conjunta y simultánea de ambos no resultara posible", teniendo en cuenta que "en todo caso, el criterio de la sostenibilidad del desarrollo será la clave de la decisión, pues deberán atemperarse las exigencias inherentes al deseable incremento de las fuentes de energía renovable con la protección de las especies y las áreas de particular sensibilidad".

En Andalucía, las instalaciones de generación eléctrica a partir de fuentes de energía renovables exigen en la mayoría de los casos de la autorización am-

\footnotetext{
${ }^{60}$ Son muchos, en efecto, los pronunciamientos que así lo evidencian. Entre otras, pueden verse las Sentencias del Tribunal Supremo de 30 de enero de 2007 (RJ 319), 30 de abril de 2008 (RJ 2503) y 26 de mayo de 2009 (RJ 6374) o las del Tribunal Superior de Justicia de Castilla y León (Sala de Burgos) de 10 de mayo (RJCA 511), 21 de mayo (Ref. Iustel 2042731) y 17 de septiembre de 2010 (JUR 368702), con cita de otras anteriores que se ocupan de esta misma cuestión.

${ }^{61} \mathrm{RJ} 6374$.
} 
biental unificada prevista en la Ley 7/2007, de 9 de julio, de Gestión integrada de la Calidad ambiental ${ }^{62}$ y regulada en el Decreto 356/2010, de 3 de agosto. Esta norma ha optado por convertir el permiso ambiental en un trámite propio del procedimiento de autorización de la instalación ${ }^{63}$. En efecto, aunque su artículo 26.2 establece con carácter general que "la autorización ambiental unificada deberá obtenerse con carácter previo a cualquier otra licencia o autorización que resulte exigible a la correspondiente actuación”, los artículos 30 y 32 excepcionan esta regla en los casos de "actuaciones privadas declaradas de utilidad e interés general de Andalucía" entre las que se encuentran "las de generación de energía". En estos supuestos, la autorización ambiental unificada "se resolverá mediante la emisión de un informe de carácter vinculante del órgano ambiental competente" en el "procedimiento seguido para la concesión de la autorización que la normativa sectorial exija en cada caso".

Prescindiendo de la regulación concreta sobre la emisión de este informe ${ }^{64}$, debe destacarse el hecho mismo de la implantación, al igual que su-

62 En efecto, en aplicación del apartado 2 del Anexo de esta Ley, la autorización ambiental unificada es exigible para "las instalaciones de producción de energía eléctrica solar o fotovoltaica en suelo no urbanizable y que ocupen una superficie superior a dos hectáreas", las "de producción de energía hidroeléctrica y los parques eólicos". Requieren, por su parte, autorización ambiental integrada "las instalaciones de producción de energía eléctrica en régimen ordinario o en régimen especial, en las que se produzca la combustión de combustibles fósiles, residuos o biomasa".

La autorización ambiental unificada constituye, en la definición que ofrece el artículo 19.3 de la Ley, una resolución en la que "se determinan, a los efectos de protección del medio ambiente, la viabilidad de la ejecución y las condiciones en que deben realizarse las actuaciones sometidas a dicha autorización ....". Estas autorizaciones se tramitan y resuelven por la Consejería de Medio ambiente e integran "todas las autorizaciones y pronunciamientos ambientales que correspondan a la Consejería competente en materia de medio ambiente y que sean necesarios con carácter previo a la implantación y puesta en marcha de las actuaciones (artículos 29 y 19.2 y 3).

${ }^{63}$ Un principio ya reconocido por el artículo 115.a) del RD 1955/2000. No obstante en Andalucía la regla, hasta la entrada en vigor del Decreto 356/2010, parece haber sido la de la tramitación independiente del permiso ambiental. Así puede comprobarse, por ejemplo, en el Boletín Oficial de la Junta de Andalucía, número 142, de 21 de julio de 2010, en el que, pocos días antes de la aprobación de esta norma, se publicaba una resolución de la Delegación provincial de Sevilla por la que se otorga autorización ambiental unificada para una planta solar.

Sobre la conexión entre la autorización energética y el permiso ambiental, vid. GIMÉNEZ CERVANTES, J., "El régimen jurídico de las energías renovables en España" (AAVV Tratado de regulación del sector eléctrico, T. I, op. cit., pág. 327).

${ }^{64} \mathrm{El}$ promotor debe presentar la solicitud de autorización ambiental integrada ante el órgano competente para la tramitación de la autorización energética que será el que deba cumplir con los trámites de información pública y consultas exigidos por la normativa ambiental.

Concluida esta fase, el órgano ambiental elaborará un dictamen ambiental "que incluirá el 
cede en otras Comunidades Autónomas como Galicia ${ }^{65}$, de un principio de unidad procedimental para la concesión de dos autorizaciones reguladas en normas diversas, que otorgan órganos administrativos distintos y que protegen bienes jurídicos diferentes. Una unidad procedimental que se logra por la vía de la conversión de la autorización ambiental unificada en un informe preceptivo y vinculante del procedimiento de autorización del anteproyecto de instalación. De esta forma, si el informe del órgano ambiental es contrario al proyecto solicitado, la autorización energética no puede otorgarse, de la misma forma en la que si el informe ambiental impone condiciones, la energética tendrá que acatarlas ${ }^{66}$. No obstante, no debe perderse de vista que el Decreto

resultado de la evaluación de impacto ambiental, así como los condicionantes que se deriven del análisis realizado por las distintas unidades administrativas afectadas y de los que resulten de los informes emitidos". Este dictamen será trasladado al órgano sustantivo, esto es, al competente para otorgar la autorización energética, y a los interesados "para que en un plazo de quince días formulen las observaciones que estimen pertinentes".

Seguidamente se elaborará "la propuesta de informe" de la que también se dará traslado "al órgano sustantivo constituyéndose, en caso de disconformidad con la misma, un grupo de trabajo mixto para resolver de común acuerdo y en el plazo máximo de treinta días los aspectos objeto de disconformidad, en los términos establecidos en el artículo 31.4".

Concluido este trámite, el órgano ambiental emitirá su informe en el plazo de ocho meses o de seis según se trate de un procedimiento ordinario o abreviado. Su contenido coincide con el previsto para la autorización ambiental unificada por el artículo 25. Las determinaciones y condiciones establecidas en el informe "se incorporarán a la autorización que otorgue el órgano sustantivo". Si éste disiente de su contenido, "podrá plantear la resolución de su discrepancia ante el Consejo de Gobierno conforme al procedimiento regulado en el artículo 33". Emitido "el informe o transcurrido el plazo para su emisión, o resuelta la discrepancia en su caso planteada, el órgano sustantivo procederá a la resolución del procedimiento de autorización conforme a la normativa sectorial aplicable, cuyo plazo quedó suspendido desde la remisión del expediente por el órgano sustantivo al órgano ambiental". Vid., en particular, artículos 21, 24, 27, 30 y 32.

65 Artículo 37.7 de la Ley 8/2009, de 22 de diciembre, por la que se regula el aprovechamiento eólico y se crean el canon eólico y el fondo de compensación ambiental.

${ }^{66}$ Como afirma, entre otras, la Sentencia del Tribunal Superior de Justicia de Castilla-La Mancha de 14 de mayo de 2007 (JUR 278774). Esta jurisprudencia insiste, no obstante, en la necesidad de que esas condiciones estén siempre debidamente motivadas. Así puede comprobarse, por ejemplo, en la Sentencia del Tribunal Supremo de 11 de octubre de 2006 (RJ 804, 2007).

Destaca también la jurisprudencia que una eventual declaración de invalidez de la decisión del órgano ambiental determina la de la autorización energética "porque además de ser un trámite de cumplimiento obligado en los procedimientos que nos ocupan, constituye una técnica transversal que condiciona la práctica totalidad de la actuación posterior, por lo que su nulidad conlleva la de la autorización impugnada”. (Sentencia del Tribunal Superior de Justicia de Castilla y León (Sala de Valladolid) de 10 de junio de 2009, JUR 344001). En el mismo sentido se había pronunciado la Sentencia de este Tribunal (Sala de Burgos) de 29 de abril de 2005 (RJCA 1085). 
356/2010 reduce su ámbito de aplicación a las instalaciones de generación eléctrica para las que la Ley de Gestión integrada de la Calidad ambiental exige autorización ambiental unificada. Para el supuesto, excepcional desde luego, en el que la autorización ambiental necesaria sea la integrada ${ }^{67}$, ha de considerarse que continuará rigiendo la independencia procedimental seguida hasta ahora.

Una mención singular merecen las instalaciones solares fotovoltaicas para las que el artículo 11.1.c) del Decreto 50/2008, que específicamente las regula, exige que la solicitud de la autorización administrativa del anteproyecto de instalación vaya acompañada de "la autorización o informe favorable del órgano ambiental competente si procede". Ahora bien, puesto que estas instalaciones están sujetas también al ámbito de aplicación del Decreto 365/2010, en la medida en que, por lo general, precisan autorización ambiental unificada ${ }^{68}$, se podrían plantear dudas sobre la solución aplicable ante la existencia de reglas de sentido contrario. De una parte, la que en la norma reguladora de estas concretas instalaciones impone la obtención previa del permiso ambiental; de otra, la que lo inserta en el procedimiento de concesión de la autorización sustantiva. Un conflicto normativo en el que entran en juego principios de contenido distinto. Así, el que aboga en favor de la norma posterior en el tiempo; y el que se decanta, de otra parte, por ese "principio de derecho" según el cual "la norma especial deroga a la norma general en cuanto a su ámbito singular de aplicación, siendo en cuanto a dicho ámbito de preferente vigencia" ${ }^{9}$.

Desde luego, estamos ante una cuestión que el Decreto de 2010 sobre la autorización ambiental unificada tendría que haber resuelto por la vía de la derogación de la regla correspondiente del Decreto sobre las instalaciones fotovoltaicas si, como parecía lógico en la medida en que con ello se satisfacen las exigencias de celeridad y simplificación de los procedimientos administrativos,

${ }^{67}$ Vid. apartado 2.4 del Anexo I.

68 Vid. Apartado 2.6 del Anexo I de la Ley 7/2007.

${ }^{69}$ En términos de la Sentencia del Tribunal Supremo de 25 de junio de 1981 (RJ 1647). En realidad, se trata de un principio firmemente mantenido tanto por la jurisprudencia civil -Sentencias del Tribunal Supremo de 22 de julio de 1994 (RJ 6583) o 20 de julio de 2001 (RJ 6863)como contencioso-administrativa -Sentencias del mismo Tribunal de de 3 de diciembre de 1962 (RJ 4646) y 25 de junio de 1981 (RJ 1647), así como Sentencias, entre otras, del Tribunal Superior de Justicia de Galicia de 9 de abril de 2001 (RJCA 195532), de Extremadura de 25 de mayo de 2000 (RJCA 1589) o de Navarra de 20 de junio de 1997 (RJCA 1285)-. 
el Gobierno andaluz quería realmente establecer un procedimiento único para todas aquellas actuaciones de utilidad o interés general en las que el permiso ambiental concurre con una autorización sustantiva a otorgar por un órgano diferente. Ahora bien, no debe pasar desapercibido el hecho de que el Decreto 9/2011 ha mantenido inalterada esa regla del artículo 11.1.c) de la norma de 2008 que exige que la solicitud de la autorización del anteproyecto de instalación se acompañe de "la autorización o informe favorable del órgano ambiental competente si procede". En definitiva, parece difícil mantener la vigencia de la norma general, el Decreto 356/2010, en detrimento de la especial, el Decreto 50/2008, cuando ésta ha sido, además, objeto de una reforma posterior a la promulgación de la disposición general en la que esta cuestión podría haber merecido otro tratamiento.

- Autorización de los órganos competentes para la protección del Patrimonio Histórico. Un informe en el procedimiento de prevención ambiental.

La construcción y puesta en funcionamiento de instalaciones de generación de energía eléctrica puede incidir también en la conservación de los valores tutelados por la Legislación de Patrimonio Histórico tal y como reconocía el "Plan de Energías renovables en España 2005-2010"70 y declara el "Plan andaluz de sostenibilidad energética 2007-2013"71. En tales casos, será necesaria la autorización administrativa prevista por el artículo 33 de la Ley 14/2007, de 26 de noviembre, del Patrimonio Histórico de Andalucía (LPHA). Ahora bien, hay que tener en cuenta que el artículo 32.2 de esta ley impone a la Consejería de Medio Ambiente el deber de recabar en los procedimientos de prevención y control ambiental "el informe vinculante de la Consejería competente en materia de Patrimonio Histórico sobre la afección al Patrimonio Histórico de la actividad proyectada", y la obliga a incluir "en las correspondientes resoluciones y pronunciamientos, las determinaciones resultantes del informe emitido, que se considerará a todos los efectos como la autorización a que se refiere el artículo 33". El plazo de emisión de este informe es de treinta días transcurridos los cuales se entenderá favorable, a menos que la actividad proyectada afecte a bienes individualmente declarados de interés cultural o incluidos en sus entornos, casos en los que, en aplicación del artículo 32.3 , el plazo se amplia a tres meses y su falta de emisión se considera desfavorable.

${ }^{70}$ Apartado 3.1.2.5 del Capítulo 3.

${ }^{71}$ Plan aprobado por el Decreto 279/2007, de 13 de noviembre. Vid. Apartado 8.2.1. 
En definitiva, con caracter general esta autorización se convierte en un informe a emitir en el procedimiento para la obtención del permiso ambiental que no podrá otorgarse si la Consejería de Cultura se opone a la actuación pretendida por razones de protección del Patrimonio Histórico. Por estos mismos motivos, la autorización ambiental deberá acatar las condiciones impuestas, en su caso, por este órgano.

\section{c) La resolución: Las vías posibles para su impugnación.}

El plazo para la resolución y notificación de la autorización es, según dispone el artículo 31.1 de la Ley de Energías renovables, de tres meses. El propio precepto prevé, no obstante, su ampliación a seis meses en los casos en los que las actuaciones objeto de autorización "no se encuentren previstas por planes o programas vigentes" ${ }^{\prime 72}$. El plazo quedará en suspenso, en aplicación del artículo 42.5 c) de la LRJ-PAC, "cuando deban solicitarse informes que sean preceptivos y determinantes del contenido de la resolución a órgano de la misma o distinta Administración por el tiempo que medie entre la petición, que deberá comunicarse a los interesados, y la recepción del informe que igualmente deberá ser comunicada a los mismos".

La resolución debe publicarse oficialmente y notificarse al solicitante y Administraciones, organismos públicos y empresas de servicio público o de servicios de interés general que hayan intervenido o que hubieran podido intervenir en el procedimiento ${ }^{73}$. En el caso de que sea favorable, ha de expresar "el periodo de tiempo contado desde su otorgamiento en el cual deberá ser solicitada la aprobación del proyecto de ejecución". De no hacerlo, se producirá su caducidad. No obstante, el interesado podrá pedir por razones justificadas una prórroga de ese plazo $^{74}$. La resolución, de otra parte, que deniegue la autorización deberá motivarse en cumplimiento del artículo 54.1.a) de la LRJ-PAC.

La falta de resolución y notificación en plazo tiene efectos desestimatorios de la solicitud de acuerdo con lo establecido en el artículo 31 de la Ley de energías renovables.

${ }^{72}$ Este plazo se reduce en el caso concreto de las instalaciones fotovoltaicas a un mes o dos, según que la competencia para resolver la tengan las Delegaciones Provinciales o la Dirección General (artículo 11.5 del Decreto 50/2008).

${ }^{73}$ El RD 1955/2000 no detalla el contenido de la resolución, lo que si hace el artículo 11.5 del Decreto 50/2008 para las instalaciones solares fotovoltaicas.

${ }^{74}$ Artículo 128.4 del RD 1955/2000. 
La resolución será lógicamente recurrible de acuerdo con las reglas generales que rigen la impugnación de los actos administrativos. Ahora bien, ha de tenerse en cuenta que en su procedimiento se insertan varios informes preceptivos y vinculantes que responden, en la mayoría de los casos, a otras tantas autorizaciones exigidas por diferentes normas sectoriales de aplicación. Es claro que el interesado podrá oponerse a estos informes con ocasión del recurso que interponga contra la eventual denegación de la autorización del anteproyecto de instalación, como expresamente indica el artículo 32.7 del Decreto 356/2010 en relación con el del órgano ambiental. Ahora bien, puede entenderse también de acuerdo con el artículo 107.1 de la LRJ-PAC que estamos ante actos de trámite susceptibles de impugnación separada. Una tesis, sin embargo, a la que el Tribunal Supremo se ha opuesto en sus Sentencias de 14 de noviembre de $2008^{75}$ y 26 de noviembre de $2010^{76}$, si bien, en ambos casos, con votos particulares del Magistrado Pérez Morate.

\section{B. La aprobación del proyecto de ejecución.}

La autorización del anteproyecto de instalación no permite por si sola el desarrollo de la actuación pretendida. Se requiere, además, la aprobación del proyecto de ejecución que, como establece el artículo 115 b) del RD 1955/2000 y reconoce la jurisprudencia en su aplicación ${ }^{77}$, es la resolución que realmente habilita para la construcción de la instalación proyectada ${ }^{78}$.

${ }^{75}$ Ref. Iustel 286404.

${ }^{76}$ Ref. Iustel 335232.

El Tribunal Supremo estima que no cabe la impugnación de la Declaración de efectos ambientales de un proyecto de planta de almacenamiento y regasificación de gas licuado toda vez que ésta "tiene un carácter instrumental o medial en relación con la decisión final de llevar a cabo un determinado proyecto; por lo que dicha declaración ambiental no constituye un acto administrativo definitivo que pueda ser impugnado de forma autónoma en la vía jurisdiccional, de manera que su enjuiciamiento sólo podrá llevarse a cabo con motivo de la impugnación que se dirija contra el acto que ponga fin al procedimiento".

${ }^{77}$ En tal sentido, Sentencia del Tribunal Superior de Justicia de Castilla-La Mancha de 18 de febrero de 2005 (JUR 91389).

78 El apartado 11 del artículo 131 del RD 1955/2000 permite que "excepcionalmente, cuando razones de urgencia o de excepcional interés para el sistema eléctrico así lo aconsejen, el Consejo de Ministros, a propuesta del Ministro de Economía, podrá autorizar motivadamente y con carácter provisional, la construcción de la instalación sin aprobación del proyecto de ejecución y siempre y cuando la instalación haya obtenido la correspondiente autorización administrativa". Una competencia que en la Comunidad Autónoma ha de entenderse otorgada al Consejo de Gobierno. 
Ahora bien, la petición de aprobación de este proyecto no ha de suceder necesariamente a la autorización del anteproyecto, toda vez que el mismo artículo 115 permite que una y otra solicitud puedan "efectuarse de manera consecutiva, coetánea o conjunta". No obstante, habrá que tener en cuenta que, como afirma la Sentencia del Tribunal Supremo de 9 de marzo de $2010^{79}$, la tramitación coetánea o conjunta "no impide lo que resulta evidente", que "en todo caso la aprobación del proyecto de ejecución ha de ser posterior a la autorización administrativa y al estudio de impacto ambiental necesario para otorgar la autorización. O, dicho en otros términos, el proyecto de ejecución ha de tener en cuenta necesariamente las observaciones y condicionamientos que en su caso establezca la autorización, normalmente como consecuencia de lo establecido en la declaración de impacto ambiental".

En el procedimiento previsto por el RD 1955/2000 para la aprobación del proyecto de ejecución destaca la obligación impuesta por el artículo 131.1 al órgano instructor de "remitir las separatas del proyecto presentado a las distintas Administraciones, organismos o empresas de servicio público o de servicios de interés general afectadas, con bienes y derechos a su cargo, al objeto de que establezcan el condicionado técnico procedente en el plazo de veinte días", garantizándose tanto a los interesados como a estas entidades el derecho a conocer y rebatir las alegaciones de la parte contraria ${ }^{80}$.

${ }^{79}$ Ref. Iustel 299281.

${ }^{80}$ Así dispone la norma que transcurridos los veinte días sin que esas instancias se hayan pronunciado se les volverá a requerir para que emitan su parecer en diez días. En el caso de no existir respuesta, "se tendrán por aprobadas las especificaciones técnicas propuestas por el peticionario de la instalación en el proyecto de ejecución”. Si, por el contrario, estas entidades manifestaran su oposición, se dará traslado de sus objeciones al interesado "para que en el plazo de quince días preste su conformidad o formule los reparos que estime procedentes". De darse esta última circunstancia, volverá a requerírseles para que, en quince días, expresen de nuevo "su conformidad o reparo". Transcurrido este plazo sin respuesta, se presumirá su acuerdo con la contestación al condicionado efectuada por el peticionario. Si persiste el desacuerdo, el órgano competente resolverá "recogiendo las condiciones técnicas establecidas en el condicionado o, bien, si discrepa de éste, remitirá propuesta de resolución al Ministro de Economía para su elevación al Consejo de Ministros", competencia que en el ámbito autonómico ha de entenderse que corresponde al Consejo de Gobierno.

Estos condicionados no son necesarios cuando las distintas Administraciones u organismos afectados hayan aprobado, de conformidad con el Ministerio o el Departamento autonómico correspondiente, normas de carácter general para el establecimiento de las instalaciones. 
La resolución, que ha de ser motivada si se opone al proyecto ${ }^{81}$, debe notificarse al peticionario y a todas aquellas Administraciones y entidades que emitieron o debieron emitir condicionado técnico. El plazo para la resolución y notificación es de tres meses, transcurridos los cuales el interesado podrá estimar denegado su proyecto de acuerdo con la regla general establecida por el artículo 31 de la Ley de Energías renovables.

\section{La autorización de explotación.}

Esta autorización permite, en términos del artículo 115 c) del RD 1955/2000, "poner en tensión las instalaciones y proceder a su explotación comercial". Se ha de solicitar una vez ejecutado el proyecto, adjuntando "un certificado final de obra suscrito por técnico facultativo competente, en el que conste que la instalación se ha realizado de acuerdo con las especificaciones contenidas en el proyecto de ejecución aprobado, así como con las prescripciones de la reglamentación técnica aplicable a la materia". Se concederá en el plazo de un mes una vez que la Administración haya efectuado las comprobaciones técnicas que considere oportunas. Durante ese plazo, el titular de la instalación puede solicitar, de conformidad con el artículo 132 de la norma, que se le extienda el acta de puesta en servicio para pruebas. El transcurso del plazo sin que la Administración se haya pronunciado o notificado su decisión tiene, de nuevo, efectos desestimatorios de la solicitud en aplicación del artículo 31.1 de la Ley de Fomento de las Energías renovables ${ }^{82}$.

\section{Autorización energética y licencia urbanística.}

Las actuaciones de "construcción o instalación de infraestructuras, servicios, dotaciones o equipamientos vinculados a la generación mediante fuentes energéticas renovables" requerirán "tras las autorizaciones que procedan de acuerdo con el resto de normas de aplicación, el otorgamiento de la correspondiente licencia urbanística municipal". Estos son los términos en los que el

${ }^{81}$ Así procede en aplicación del artículo 54.1 de la LRJ-PAC como destaca, por ejemplo, la Sentencia del Tribunal Superior de Justicia de Castilla-La Mancha de 18 de febrero de 2005 (JUR 91389).

${ }^{82} \mathrm{El}$ artículo 12 del Decreto 50/2008 regula, en términos que no difieren sustancialmente de los establecidos en la disposición estatal, la puesta en servicio de las instalaciones solares fotovoltaicas. 
artículo 12.7 de la Ley de Fomento de las energías renovables recoge la que, de otra parte, constituye una exigencia clara en aplicación del artículo 169 de la Ley 7/2002, de Ordenación urbanística de Andalucía (LOUA): el necesario sometimiento a licencia urbanística "de todos los actos de construcción o edificación e instalación y de uso del suelo, incluidos el subsuelo y el vuelo". La licencia urbanística se ha de obtener, como dispone ese mismo artículo 12.7, cuando ya se cuenta con el resto de las autorizaciones necesarias para la instalación proyectada. Una norma que está en sintonía, de nuevo, con la regla general establecida por el artículo 172.1 de la LOUA, pero que puede, sin duda, presentar problemas en su aplicación.

En efecto, la independencia de la licencia urbanística del resto de las autorizaciones precisas para la instalación y su concesión cuando todas éstas ya han sido otorgadas conlleva el peligro de que el Municipio pueda dar al traste con una operación que, tras laboriosos procedimientos, cuenta ya con una declaración de conformidad con el ordenamiento jurídico atendiendo a la protección de intereses muy diversos. Es cierto que el informe de compatibilidad urbanística emitido por el Municipio con carácter previo a la solicitud de la autorización energética viene a paliar considerablemente este riesgo aunque, desde luego, no garantiza la conformidad municipal con la instalación. Y es que no parece que pueda aceptarse que el Municipio se encuentra vinculado en la concesión de la licencia por su propio informe emitido meses antes, teniendo en cuenta además que el proyecto de instalación sobre el que se pronunció en su día ha podido variar en el curso del procedimiento a resultas, en los supuestos más frecuentes, de los condicionamientos introducidos por el órgano ambiental.

Desde luego, no cabe negar la plena facultad del Municipio para pronunciarse en contra de su propio informe en los supuestos en los que entre el momento de su emisión y el del otorgamiento de la licencia se haya producido una variación del régimen jurídico aplicable o una alteración del presupuesto de hecho que sirvió de base para su emisión. Más discutible podría resultar su capacidad para separarse de ese informe previo en los supuestos en los que las condiciones en las que éste se emitió no hayan variado, hipótesis en las que una separación de su criterio anterior no encontraría más fundamento que el de una distinta interpretación del ordenamiento jurídico aplicable o una diferente valoración de las circunstancias concurrentes en el ejercicio de unas potestades que, aunque ciertamente regladas, se insertan con claridad en el ámbito de la discrecionalidad técnica. Ahora bien, aun en estos casos y aunque sea difícil ofrecer una respuesta uniforme a situaciones reales que pueden ser muy variadas, quizá, y con carácter general, deba mantenerse la capacidad del Muni- 
cipio para separarse de su informe de compatibilidad urbanística siempre y cuando justifique debidamente su decisión. Otra solución supondría aceptar licencias municipales que, a juicio de la Administración en el momento de su concesión, no son las que mejor defienden los intereses públicos en juego. Aceptada esta premisa, podrá, desde luego, plantearse la cuestión relativa a los posibles derechos de los interesados en estos casos en los que la licencia municipal se aparta del informe de compatibilidad previamente emitido, tema que ha de reconducirse, como es obvio, al ámbito de la responsabilidad patrimonial de los Poderes públicos.

\section{La concesión de instalación acogida al régimen especial de producción.}

La producción de energía a partir de fuentes renovables se ve, por lo general, beneficiada por la aplicación de un régimen especial caracterizado por las ventajas económicas que comporta para el productor. El reconocimiento de este específico régimen se ha visto afectado de manera importante por la reforma del RD 661/2007 por el 198/2010, de 26 de febrero, de adaptación de determinadas normas del sector eléctrico a la Ley 25/2009. La condición de instalación acogida a este específico régimen se otorga, según establece el reformado artículo 6.1, "por la Administración competente para su autorización en el momento de la inscripción previa en el Registro administrativo de instalaciones de producción en régimen especial" 83 . Desaparece así la necesidad de obtener esa condición con carácter previo a la inscripción en el registro, nota que caracterizaba al Derecho anterior a la reforma del RD 198/2010

Interesa advertir, además, que tras la modificación operada por esta disposición la solicitud de reconocimiento del régimen especial de producción exige la previa ejecución de la instalación toda vez que entre la documentación acreditativa que, por disposición del artículo 11.2 del RD 661/2007, ha de presentarse junto con la solicitud de inscripción en el registro figura "el acta de

${ }^{83}$ Este registro se regula en la Sección $3^{\text {a }}$ del Capítulo II, artículos 9-15, del RD 661/2007. Vid., en particular, su artículo 11.

84 Consecuentemente, el RD 198/2010, de 26 de febrero, deroga los artículos 7-9 del RD $661 / 2007$, que establecían el procedimiento para la obtención de instalación acogida al régimen especial.

Sobre las características del régimen establecido por el RD 661/2007 antes de su reforma, puede verse LÓPEZ SAKO, M.J., Regulación y autorización de los parques eólicos, op. cit., págs. 212-230. 
puesta en servicio provisional para pruebas". En realidad, ésta es una exigencia que ya aparecía en la redacción originaria de este precepto pero a los solos efectos de una inscripción de la que entonces no dependía la concesión del régimen especial de producción ${ }^{85}$. Nos hayamos, sin duda, ante una novedad importante y de trascendentes efectos prácticos. A partir de ahora, el promotor habrá de proceder a esa ejecución sin saber si gozará o no de los beneficios propios de este régimen lo que, quizá, no contribuya al proclamado fomento de las fuentes de energías renovables.

El carácter básico de esta normativa ha determinado que la Junta de Andalucía en su reciente Decreto 9/2011 haya derogado el artículo 8 del Decreto 50/2008, de 19 de febrero sobre "otorgamiento de la condición de instalación de producción acogida a Régimen especial", y dado una nueva redacción al 13 para, en sintonía con lo dispuesto por el Derecho estatal, establecer que la condición de producción en régimen especial será, en todo caso, otorgada "en el momento de la inscripción previa en el Registro de Instalaciones de Producción en Régimen Especial de la Comunidad Autónoma de Andalucía"86.

\section{CONSIDERACIÓN FINAL. ¿ES NEGESARIA O CONVENIENTE LA REFORMA DEL RÉGIMEN VIGENTE?}

Son muchas las disposiciones que, de una u otra forma, recogen la necesaria reforma del régimen de las energías renovables para, entre otros objetivos, lograr que "los procedimientos administrativos se racionalicen y se aceleren en el nivel administrativo adecuado" ${ }^{27}$. Unos objetivos que también fi-

${ }^{85} \mathrm{El}$ apartado 2 del entonces artículo 6 se refería escuetamente a la necesaria exposición en la solicitud de las "características técnicas y de funcionamiento de la instalación".

${ }^{86}$ Debe advertirse que la nueva norma de Andalucía, al igual que la estatal, dispone que la solicitud de ese régimen e inscripción en el registro debe producirse, según determina el reformado artículo 13.1, "una vez ejecutada la instalación solar fotovoltaica", requisito que antes era necesario para poder pedir la inscripción en el Registro, pero no para solicitar y obtener, en aplicación del suprimido artículo 8, la condición de instalación acogida al régimen especial de producción.

${ }^{87}$ En términos tomados, por ejemplo, de la Directiva 2009/28, de 23 de abril, de fomento del uso de energía procedente de fuentes renovables. 
guran en el "Plan de acción de energías renovables (PANER) 2011-2020"88 y a los que claramente apunta, de otra parte, la Ley de economía sostenible, que aboga con carácter general por "un marco normativo sencillo, claro y poco disperso, que facilite el conocimiento y la comprensión del mismo" y, en particular, por unos procedimientos administrativos "adecuados a las distintas tecnologías, tamaños y usos" que eliminen "barreras técnicas, administrativas y de mercado" y establezcan "plazos abreviados de respuesta" y "tasas y gravámenes reducidos y uniformes" ${ }^{\prime 89}$.

La realidad actual está lejos de estos loables propósitos. Ni en el marco normativo vigente puede calificarse de sencillo y claro, ni los procedimientos administrativos se caracterizan por esas deseadas notas de rapidez y agilidad. Ahora bien, sin negar la obligación de avanzar en esta línea, no pueden dejar de reconocerse las muchas dificultades del camino por andar. De entrada, ha de tenerse presente que nos encontramos ante la aplicación de un Derecho ordenador de una realidad extraordinariamente compleja y sujeta, además, a continuos avances tecnológicos que son los que, en la generalidad de los casos, propician los muchos cambios normativos que se producen en el sector. El propio Tribunal Supremo, en relación concretamente con la energía eólica, ha manifestado en numerosas ocasiones que el ordenamiento jurídico en la materia "no ha alcanzado", todavía, "quizá por su reciente implantación, un grado de madurez suficiente" 90 , lo que "nos exige a todos un importante esfuerzo de estudio y adaptación" 91 .

${ }^{88}$ Plan que incluye entre las medidas necesarias para alcanzar los objetivos propuestos "el desarrollo de un marco adecuado para la simplificación, homogeneización y unificación de los procedimientos de autorización de instalaciones EERR incluyendo la simple notificación". (Vid. Capítulo IV).

${ }^{89}$ Artículos 4.7 y 84.3 de la ley $2 / 2111$, de 4 de marzo.

El artículo 84 dispone, además, que "el Ministerio de Industria, Comercio y Turismo elaborará un catálogo de los procedimientos y trámites a seguir para la implantación de instalaciones de aprovechamiento de la energía de origen renovable y cogeneración de alta eficiencia al objeto de servir de guía a las administraciones competentes para la elaboración de los mismos, así como orientar a los promotores de este tipo de instalaciones".

${ }^{90}$ Sentencias, entre otras, de 28 de marzo de 2006 (RJ 1115), 26 de junio de 2006 (RJ 3974) y 30 de enero de 2007 (RJ 319).

${ }^{91}$ Sentencia de 30 de abril de 2008 (RJ 2503).

92 Si se quiere, declara, "que la nueva planificación energética de Andalucía para los próximos años alcance su objetivo fundamental de garantizar el suministro energético suficiente y 
Tampoco, desde otra perspectiva, puede perderse de vista que la construcción y funcionamiento de instalaciones de generación eléctrica constituyen actividades en las que concurren bienes y valores jurídicos de muy distinta naturaleza y no siempre de fácil armonización. El suministro de energía eléctrica es, como afirma la Exposición de Motivos de la LSE, "esencial para el funcionamiento de nuestro sociedad", de ahí que deba garantizarse, en todo momento, en las condiciones de seguridad y calidad que las propias normas determinan. Ahora bien, ésta es una actividad que ha de atender igualmente a los requerimientos impuestos por la protección del medio ambiente, objetivo al que se ordena un importante conjunto normativo encabezado por el artículo 45 de la Constitución, así como, de otra parte, a los condicionamientos derivados de la ordenación territorial y urbanística. También, en su caso, la construcción y funcionamiento de instalaciones de generación eléctrica habrá de tener en cuenta las exigencias establecidas por las normas de protección del patrimonio cultural, la defensa nacional o cualesquiera otras que puedan resultar de la aplicación de otras Leyes sectoriales. En definitiva, en las actividades de esta naturaleza confluyen intereses muy diversos tutelados por normas diferentes cuya aplicación está, además, encomendada a órganos administrativos distintos, de ahí esa multiciplidad de procedimientos y autorizaciones dificil, por consiguiente, de soslayar.

A las dificultades derivadas de esta concurrencia de intereses, deben añadirse, además, las que aporta la fuerte descentralización que caracteriza al Estado español actual. En efecto, en un modelo en el que las Comunidades Autónomas cuentan con importantes competencias en el ámbito no solo de la energía, sino también en los del medio ambiente, la ordenación del territorio, el urbanismo, el patrimonio cultural o el propio procedimiento administrativo, es muy difícil la consecución de un régimen uniforme para la concesión de los distintos permisos que la construcción y puesta en funcionamiento de una instalación eléctrica requiere.

Ahora bien, el reconocimiento de las dificultades que se oponen al logro de esos objetivos de mayor claridad y simplificación de los procedimientos, no puede servir de excusa para la adopción de aquellas medidas que contribuyan a avanzar en esta línea, lo que probablemente exija reflexionar con carácter previo sobre algunas de las grandes opciones del Derecho regulador del sector eléctrico como son, señaladamente, las que se refieren al mantenimiento como actividades reguladas del acceso a las redes de transporte y distribución o a la atribución de funciones públicas a entidades privadas, proceso que, sin embargo, no ha encontrado, hasta ahora, una adecuada traducción en el ámbito del procedimiento administrativo. En efecto, este es un fenómeno que, en buena lógica, debería llevar aparejado una regulación 
sobre la forma de actuación de estas entidades cuando ejercen funciones de esta naturaleza y sobre las garantías que ante ellas asisten a los interesados. En definitiva, a los promotores de estas instalaciones ha de ofrecérseles seguridad jurídica, el convencimiento de que, cumplido ese procedimiento, su instalación va a ser posible y, lo que es más importante, que proyectos de tanta envergadura como éstos, objeto de una larga tramitación y extraordinariamente costosos no se verán afectados por cambios normativos adoptados sin las correspondientes garantías.

$\mathrm{Al}$ margen de todo ello, y con la atención centrada exclusivamente en el ordenamiento de Andalucía, parece clara la conveniencia de una norma general que sin perjuicio de las especialidades que realmente puedan requerir determinadas fuentes de energías renovables, establezca una ordenación acabada que ponga fin a la actual dispersión normativa existente en un ámbito ya de por si complicado y necesitado, por consiguiente, de claridad. Una ordenación precisada a su vez, como reconoce el "Plan andaluz de sostenibilidad energética 2007-2013"92, de un adecuado engarce con esas otras muchas disposiciones encargadas de la tutela de los variados intereses públicos concurrentes en la construcción y puesta en funcionamiento de instalaciones de generación eléctrica.

Confiemos, en fin, en que las numerosas normas en proyecto tanto en el Estado como en Andalucía sean capaces de establecer unos procedimientos que cumplan realmente con los requerimientos exigidos por el ordenamiento comunitario. El propósito, desde luego, no es fácil pero en su consecución se juega en buena medida la verdadera implantación de estas fuentes de energía y con ella la contribución decidida al logro de esos objetivos medioambientales convertidos en una de las mayores preocupaciones de nuestra sociedad y en uno de los compromisos más firmes de una política a nivel mundial. Ahora bien, el desarrollo de las energías renovables no solo aporta beneficios desde la óptica medioambiental, presenta también una dimensión económica que, en modo alguno, puede soslayarse, pues son estas las fuentes en las que la Unión europea "dispone de cierto margen de maniobra para aumentar la oferta" y consecuentemente disminuir la dependencia energética exterior ${ }^{93}$.

de calidad para todos los andaluces, que contribuya al desarrollo de Andalucía siempre bajo condiciones de sostenibilidad económica, social y ambiental, es imprescindible una mayor integración con otras políticas sectoriales mediante un diálogo permanente y una acción conjunta con todos los agentes implicados.

${ }^{93}$ Vid. "Libro verde. Hacia una estrategia europea de seguridad del abastecimiento energético" que vio la luz en el año 2000. 